\title{
Replenishment, production and quality control strategies in three-stage
}

\section{supply chain}

\author{
R. Hlioui ${ }^{\mathrm{a}}$, A. Gharbi ${ }^{\mathrm{a}}$, A. Hajji ${ }^{\mathrm{b}}$ \\ ${ }^{a}$ Department of Automated Production Engineering, Production System and Control Laboratory, \\ École de technologie supérieure. Université du Quebec, Montreal, QC, Canada \\ ${ }^{\mathrm{b}}$ Department of Operations and Decision Systems \& CIRRELT, Laval University, Québec, QC, \\ Canada
}

\section{Abstract:}

In this paper, we propose to jointly integrate and coordinate production, replenishment and quality inspection decisions in a three-stage supply chain control problem. The transformation stage produces one final product type and responds to a stable market demand. After a random lead time, the supplier delivers raw materials in batches which may contain a certain proportion of defective items. When a lot of raw materials is received, a lot-by-lot acceptance sampling plan is applied, and then a decision is taken with regards to a $100 \%$ screening or discarding of the sampled lot. In this article, we focus on the existing interaction between the applicable quality control decisions and the replenishment and production control decisions. The objective is to determine a control policy for production, replenishment and quality activities which minimizes the total cost, including purchasing costs, production and quality inspection costs, as well as the inventory/backlog costs. A simulation model and a response surface methodology are used to find the optimal parameters of the proposed policy. The obtained results show that the integration of $100 \%$ screening or discarding decisions in a new "hybrid" one is more beneficial, and guarantees a better coordination at a lower cost.

Keywords: Stochastic optimal control, Unreliable manufacturers, Replenishment, Imperfect quality, Acceptance sampling, Simulation, Response Surface Methodology (RSM). 


\section{Introduction}

In today's economy, an adequate management of a supply chain is necessary in order to ensure the survival of industries, and allow them to increase their competiveness. Several recent studies have shown that decision making models incorporating raw material procurement in manufacturing activities perform better in terms of average total cost than those tackling the decisions involved separately (Lee, 2005). In this context, Ben-Daya and Al-Nassar (2008) studied a coordinated inventory and production problem in a threelayer supply chain involving suppliers, manufacturers and retailers. Sawik (2009) developed a mixed integer programming approach where manufacturing, supply and assembly schedules are determined simultaneously. Pal et al. (2010) suggested an integrated procurement production and shipment planning for a three-echelon supply chain. Sajadieh et al. (2013) considered an integrated production-inventory model for a three-stage supply chain in which lead times to retailers are stochastic. All these studies provide valuable contributions to the scientific literature; however, they do not consider the dynamic evolution of manufacturing activities and the impact of this evolution on complete decisions.

Many research studies have tackled the problem in a dynamic stochastic context where the control theory has been one of the most significant approaches used to solve such problems. In the context of the planning problem for unreliable manufacturing systems, several approaches have been developed based on the hedging point policy (HPP) concept (Kenné and Gharbi, 2000). This policy consists in building an optimal safety stock level during periods of excess capacity in order to meet demand when the manufacturing system is no longer available due to machine failure. Sethi and Zhang (1999) suggested a solution for an optimal production planning where multiple distinct part types are produced. Kenné et al. (2003) considered an integrated production and corrective maintenance problem. Pellerin et al. (2009) developed a production control problem for multi-production-rate remanufacturing systems. Rivera-Gómez et al. (2013) studied an integrated production, overhaul and preventive maintenance problem.

Following the works of Lee (2005), Hajji et al. (2009) addressed an integrated production and supply control problem for a three-stage supply chain with one unreliable supplier 
and one unreliable transformation stage. Hajji et al. (2009) showed that the optimal control policy is a "modified state-dependent multi-level base stock policy" (MBSP) for production activities, combined to a "state-dependent economic order quantity" (SDEOQ) policy for replenishment decisions. The developed policy allows the identification of the best decision to undertake as a function of the whole system state. Berthaut et al. (2009) determined a control policy for both supply and remanufacturing activities, composed of a multi-hedging point policy (MHPP) and an (s,Q) policy. Song (2009) considered a supply chain with supplier, manufacturer and customer with stochastic leadtime, processing time and demand and determined the optimal integrated ordering and production policy that minimise the expected total cost subject to finite capacitated warehouses. Hajji et al. (2011a) studied a joint production and delayed supply control problem. They showed that the control policy is a combined (HPP) and (s,Q) policy. Hajji et al. (2011b) extended the model of Hajji et al. (2009) to a multiple supplier case. These research studies showed the advantages considering the production and supply activities in a dynamic stochastic context in an integrated manner. Song (2013) studied several stochastic supply chain systems and determined the optimal production control policies and the optimal ordering policies in the case of supply chains with backordering and, a supply chain with multiple products, etc. However, they all assume raw materials to be in perfect quality. This assumption is unrealistic, as has been argued by many research studies (Konstantaras et al., 2012) and (Khan et al., 2014). In fact, the lot received may contain a fraction of non-conforming parts. Therefore, to identify and separate bad purchased items from good ones, the inspection/screening process becomes an indispensable step.

This paper proposes to study this issue through the integration of production, replenishment and raw material quality control in a three-stage supply (SupplierManufacturer-Customer) chain. Upon the lot being received, the manufacturer performs a single acceptance sampling plan. Such a policy has indeed been largely adopted in the industry (Schilling and Neubauer, 2009). Starbird (1997) and Starbird (2005) analyzed the impact of a buyer's acceptance plan on a supplier's quality and production decisions. Ben-Daya and Noman (2008) established integrated inventory inspection models with and without replacement of non-conforming items. They proposed a comparative study 
between different inspection policies: no inspection, sampling inspection and 100\% inspection. Al-Salamah (2011) studied an EOQ model where the quality of the received lot is controlled by a destructive acceptance sampling. Wan et al. (2013) studied the incentive effect of acceptance sampling plans in a supply chain with endogenous product quality. More recently, a few articles have studied supply chain problems with nonconforming raw materials, but however, with the focus solely a full inspection policy (Sana, 2011), (Pal et al., 2012) and (Sana et al., 2014).

It should be noted that when an acceptance plan is applied, the inspected raw materials lot may be refused. However, in all of the previous research studies, only one of the two decisions was taken with respect to the rejected lots: either $100 \%$ inspection or the entire lot is returned to the supplier. While this assumption may be reasonable for certain circumstances, it could present limitations if considered jointly with the production process and the customer demand stage. As a three stage supply chain is considered, the quality decision should not be taken independently of the whole system. The question then becomes how the decision maker should proceed in taking such inspection decisions? On the one hand, returning a lot to the supplier reduces the total cost of the inspection operation, but it increases the lead time, and results in an important finished product shortage risk. On the other hand, although a $100 \%$ inspection decision may assure the presence of better quality raw materials, the system will face high inspection costs. To arrive at a compromise between the advantages and disadvantages of return and $100 \%$ inspection decisions of rejected lot, we propose, in this article, that quality inspection decisions be coordinated with production and replenishment activities to ensure better control at minimal cost.

The rest of this paper is organised as follows. In section 2, we present a formulation of the production, supply and inspection problem. In section 3, we propose a control policy of the system. We report a resolution approach in section 4 and a simulation model in section 5. In section 6, we give an example to present the numerical results. In section 7 , we illustrate a comparative study between different inspection policies. Finally, conclusions are given in section 8 . 


\section{Problem formulation}

The purpose of this section is to introduce the considered problem which consists of an integrated unreliable manufacturing system supplied by an upstream supplier with random lead time, using a sampling plan to control received raw materials.

\subsection{Notations}

The notations used in this paper are summarized as follows:

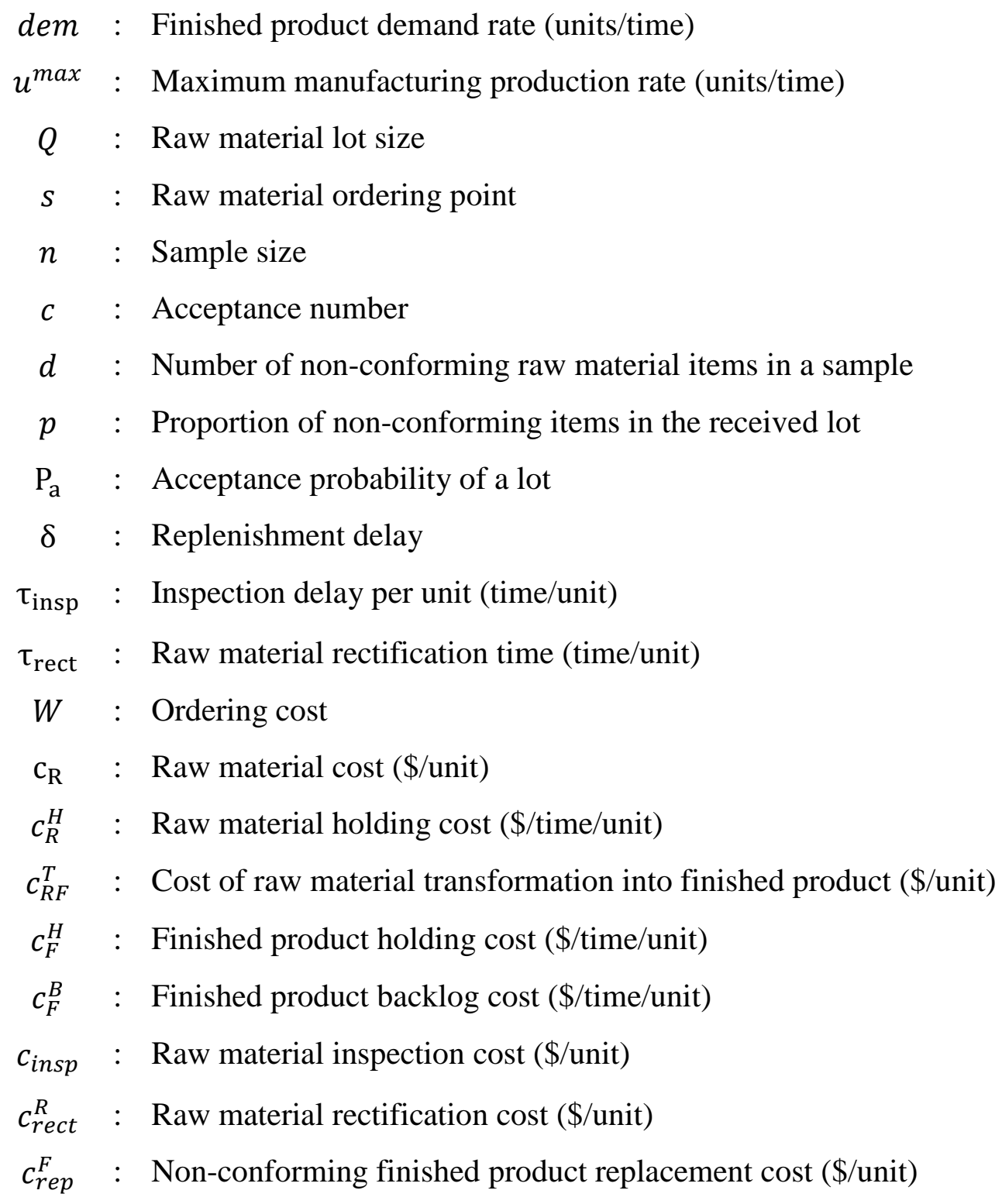




\subsection{Problem statement}

The system under study (Fig. 1) consists of one supplier, one manufacturer and one customer. The manufacturer (stage 2) orders a batch of products from an upstream supplier, with an ordering cost $W$ and a purchasing price $c_{\mathrm{R}}$ per unit. The supplier (stage 1) delivers the lot after a random lead time $\delta$. We assume that each delivered lot contains a fixed fraction $\mathrm{p}$ of non-conforming items and that the manufacturer (stage 2) could be unavailable due to failures and repair operations.

After the raw materials are transformed into finished products, the manufacturer sells them to the final customer (stage 3 ) and responds to a continuous and constant demand rate dem.

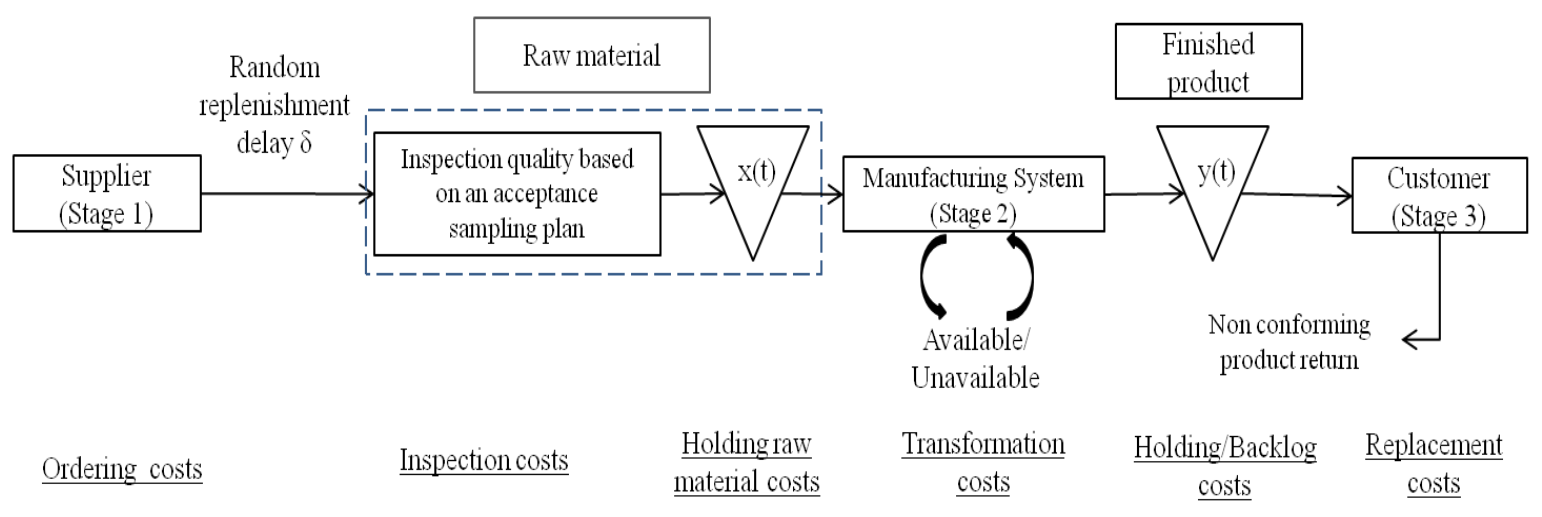

Fig. 1: System under study

When the lot is delivered, the manufacturer inspects its quality using a lot-by-lot single acceptance sampling plan with attributes. Because a sampling plan is adopted, some unsafe product may pass inspection. These items could be transformed into a finished product, and thus sold to the final customer. In this case, it is assumed that the customer can detect and return them to be replaced with a $c_{\text {rep }}^{\mathrm{F}}$ per unit cost.

The whole state of the considered supply chain at time $t$ is described by a hybrid state where both a discrete and a continuous component are used, namely:

- A continuous part $y(t)$ which describes the cumulative surplus level of the finished product (inventory if positive, backlog if negative). This part faces a continuous downstream demand. 
- A piecewise continuous part $x(t)$ which describes the cumulative surplus level of the raw material. This part faces a continuous downstream demand (i.e., a manufacturing production rate) and an impulsive upstream supply after a lot-by-lot sampling inspection.

- A discrete part $\alpha(t)$ which describes the state of the manufacturing system. This state can be classified as "manufacturing system is available", denoted by $\alpha(t)=1$, or "manufacturing system is unavailable", denoted by $\alpha(t)=2$.

Assuming a perfect production process, we consider that the quality of our raw material and finished product are equivalent. Thus, the dynamic of the stock levels $x(t)$ and $y(t)$ is given by the following differential equations:

$$
\begin{gathered}
\dot{y}(t)=u(t, \alpha)-\frac{d e m}{1-A O Q(t)}, y(0)=y_{0} \forall t \geq 0 \\
\left.\dot{x}(t)=-u(t, \alpha), x(0)=x_{0} \forall t \in\right] \xi_{i}, \xi_{i+1}[ \\
x\left(\xi_{i}^{+}\right)=x\left(\xi_{i}^{-}\right)+Q_{i} \forall i=1 \ldots N
\end{gathered}
$$

where $y_{0}, x_{0}$ denote the initial stock levels, dem denotes the demand rate, $u(t, \alpha)$ denotes the manufacturing system production rate in mode $\alpha, A O Q(t)$ denotes the average outgoing quality of the raw material, and $\xi_{i}^{-}, \xi_{i}^{+}$denote the negative and positive boundaries of the $N$ receipt instants after an inspection operation, respectively.

\section{Structure of control policies}

In this section, we present the structure of the control policies for the considered system. The production and supply policies are based on the findings of Hajji et al. (2011a) and Bouslah et al. (2013). Regarding the quality control policy, we will study three different inspection decisions which will be presented later. In this study, our main objective is to determine the production rate, a sequence of supply decisions and the best quality control policies, in order to minimize the total expected supply, production, quality inspection, raw material holding, holding/backlog final product costs and the defective finished product replacement cost. 


\subsection{Production and supply policies}

For the same class of supply chain in a stochastic dynamic context, where the manufacturing system is facing a delayed supply, and without consideration of quality, Hajji et al. (2011a) determined the optimum decision variables consisting of the production rate $\mathrm{u}($.$) and the sequence of supply orders denoted by$ $\Omega=\left\{\left(\theta_{0}, Q_{0}\right),\left(\theta_{1}, Q_{2}\right), \ldots\right\}$, where $Q_{i}$ is the order quantity derived at time $\theta_{i}$. Indeed, Hajji et al. (2011a) showed that the optimal control policy for a joint production and replenishment problem is defined by a combined Hedging Point Policy (HPP) and (s, Q) policies.

Recently, Bouslah et al. (2013) jointly considered the production control policy and a single sampling plan design for an unreliable batch manufacturing system. By considering an imperfect production system, they showed that their production policy is controlled by a "Modified Hedging Point Policy" (MHPP).

According to the findings of Hajji et al. (2011a), the raw material inventory and the final product should be maintained at an excess level in order to face supply operations, maintenance operations, and capacity shortage. However, as some unsafe raw materials may pass inspection, the production policy is controlled by the MHPP policy rather than the HPP policy. Consequently, more appropriate supply and production control policies, where the supplied lot contains non-conforming items is proposed as follows:

\section{Production policy (MHPP):}

$$
u(.)=\left\{\begin{array}{l}
u^{\max } \text { if }(y(t)<Z) \text { and }(x(t)>0) \text { and } \\
(\alpha=1) \\
\frac{d e m}{1-A O Q(t)} \quad \text { if }(y(t)=Z) \text { and }(x(t)>0) \text { and } \\
(\alpha=1) \\
\text { 0, otherwise. }
\end{array}\right.
$$

Supply policy $(S, Q)$ :

$$
\Omega(.)=\left\{\begin{array}{l}
Q \text { if } x<s, Q \in \mathbb{N} \\
8
\end{array}\right.
$$




$$
0 \text {, otherwise. }
$$

With constraint: $Z \geq 0, Q>s \geq 0$.

Where: $\mathrm{u}^{\max }$ denotes the maximum production rate, $\mathrm{s}$ the ordering point, $\mathrm{Q}$ the lot size, and $\mathrm{Z}$ the finished product hedging level.

\subsection{Inspection policies}

A single sampling plan is characterized by two parameters, $n$ and c, which are the sample size and the acceptance number, respectively. If the number of defective items $d$, found in this sample, is equal to or less than $c$, the lot will be accepted, otherwise it will be rejected. In this study, we consider the following three scenarios: a single sampling plan with $100 \%$ inspection and rectification operations (100\% policy), a single sampling plan with return decision (Ret policy), and a single sampling plan leading to a combination of the two last decisions, called the Hybrid policy (Hyb policy).

Given the aforementioned quality control parameters $(n, c, d, \mathrm{p})$, the probability of acceptance of the received lot $\mathrm{P}_{\mathrm{a}}$ can be calculated using the binomial probability distribution (Schilling and Neubauer, 2009) which is given as follows:

$$
P_{a}=P\{d \leq c\}=\sum_{d=0}^{c} \frac{n !}{d !(n-d) !} p^{d}(1-p)^{n-d}
$$

\subsubsection{Description of the $100 \%$ policy}

Fig. 2 presents the evolution of an $\mathrm{i}^{\text {th }}$ lot from the launch of an order $\theta_{\mathrm{i}}$ to its admission in the raw materials stock $\xi_{\mathrm{i}}$ and the incurred quality costs in the case of the $100 \%$ policy. As soon as the lot is received at instant $\omega_{i}=\theta_{i}+\delta$, a sample size $n$ is screened with $n$. $\tau_{\text {insp }}$ delay and $n . c_{\text {insp }}$ costs, where $\tau_{\text {insp }}$ is the inspection delay per unit and $c_{\text {insp }}$ is the inspection cost per unit. Inspired by the works of (Rosenblatt and Lee, 1986) and (Gholami-Qadikolaei et al., 2013), we assume that non-conforming items are reworked with a $\tau_{\text {rect }}$ delay per unit and a $c_{\text {rect }}^{R}$ per unit cost. According to inspection decisions, the instant $\xi_{\mathrm{i}}$ may take two values (Fig. 2). If the lot is accepted, $\xi_{\mathrm{i}}=\omega_{i}+n \tau_{\text {insp }}+d \tau_{\text {rect }}$. Otherwise, $\xi_{i}=\omega_{i}+Q \cdot \tau_{\text {insp }}+p \cdot Q \cdot \tau_{\text {rect }}$, where $p \cdot Q$ is the number of non-conforming 
items in lot $Q$. Indeed, if the lot is refused, it will be subject to a $100 \%$ screening process and, all non-conforming items will be reworked (Fig. 2-(^).

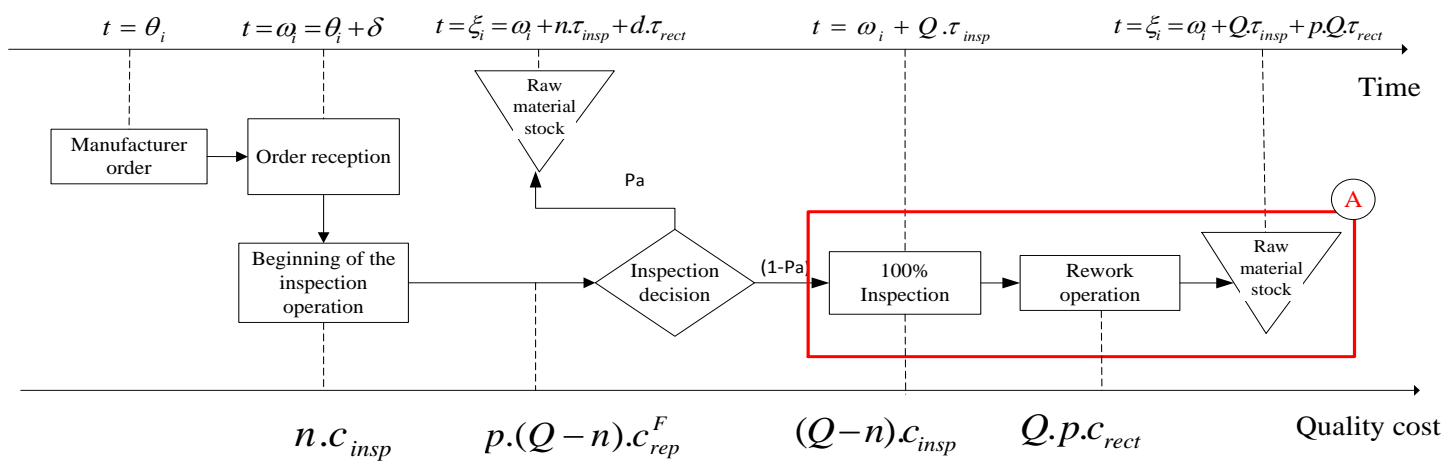

Total cost $=$ Supply cost + Quality cost + Raw material inventory cost + production cost + finished product inventory and backlog cost

Fig. 2: $100 \%$ policy

\subsubsection{Description of the Ret policy}

Fig. 3 presents the evolution of an $\mathrm{i}^{\text {th }}$ lot from the launch of an order $\theta_{\mathrm{i}}$ to its reception in the raw materials stock $\xi_{\mathrm{i}}$ and the incurred quality costs in the case of the Ret policy. As soon as the lot is received at instant $\omega_{i}=\theta_{i}+\delta$, the manufacturer controls the quality of a sample size $\mathrm{n}$. If the inspected lot is accepted, non-conforming items are reworked with a $\tau_{\text {rect }}$. Thereafter, it is added to the raw materials stock (Fig. 3-B) at $\xi_{\mathrm{i}}=\omega_{\mathrm{i}}+$ n. $\tau_{\text {insp }}+d \tau_{\text {rect }}$. However, if the lot is rejected, the supplier picks it up and a new order is placed. In that situation, we assume that the manufacturer will not pay the supplier (no ordering and purchasing costs). After an additional delay $\delta$, a new lot is delivered and an additional quality control is performed. Thus, $\xi_{\mathrm{i}}=\omega_{\mathrm{i}}+\mathrm{N}_{\mathrm{rej}}^{\mathrm{i}} \cdot \delta+\left(\mathrm{N}_{\text {rej }}^{\mathrm{i}}+1\right) n \cdot \tau_{\mathrm{insp}}+$ $d \tau_{\text {rect }}$, where $\mathrm{N}_{\text {rej }}^{\mathrm{i}}$ is the number of times the $\mathrm{i}^{\text {th }}$ lot is rejected. 


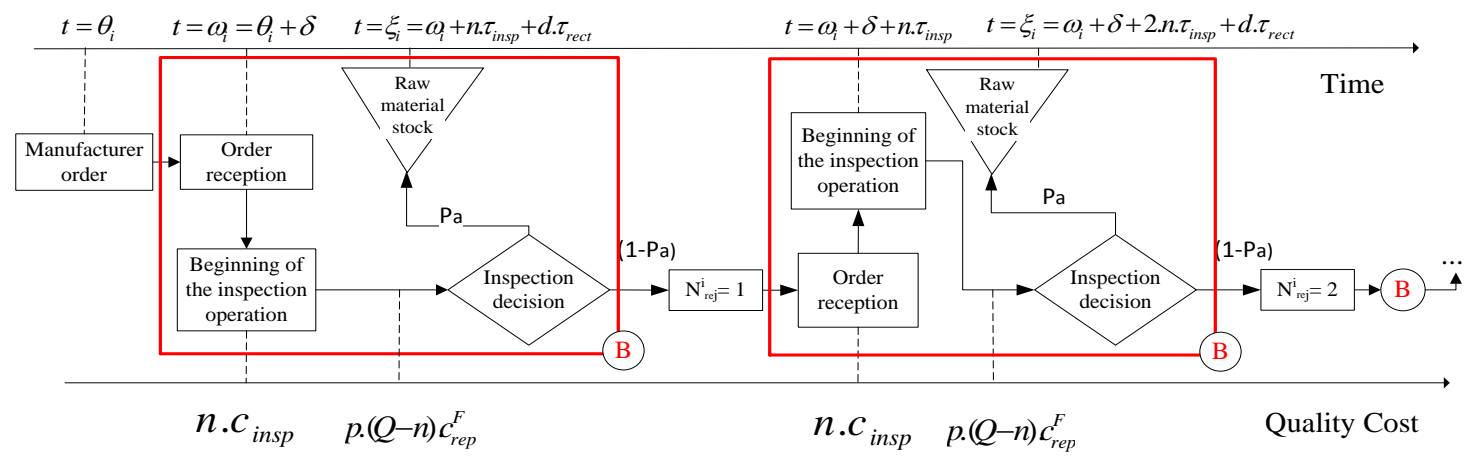

Total cost $=$ Supply cost + Quality cost + Raw material inventory cost + production cost + finished product inventory and backlog cost

Fig. 3: Ret policy

\subsubsection{Description of the Hyb policy}

As shown in Fig. 3, the return decision causes an increase in the delivery delay. Therefore, this decision may reduce the availability of raw materials, leading to a stoppage of the production process due to starvation and an increase in the backlog cost of the final product due to continuous customer demand. In a different context, performing a $100 \%$ inspection on each refused lot (Fig. 2) could considerably increase the inspection and rectification costs. Nevertheless, if there is a significant stock of finished products, no additional raw materials are needed. Thus, it would be better to return the refused lot in order to avoid such additional costs. That is why it is reasonable to assume that it would be more appropriate to decide whether or not to return the rejected lot, depending on the finished product level. If the finished product stock level is above a threshold $\mathrm{Z}_{2}$, the manager considers that the system has enough finished products to reduce the risk of backlog and returns the refused lot to the supplier (Fig. 4-C). Otherwise, the manager will opt for a $100 \%$ inspection and rectification operations to ensure the continuity of the production process. Fig. 4 presents the evolution of an $\mathrm{i}^{\text {th }}$ lot from the launch of an order $\theta_{i}$ to its reception in the raw materials stock $\xi_{i}$ and the incurred quality costs in the case of the Hyb policy. 


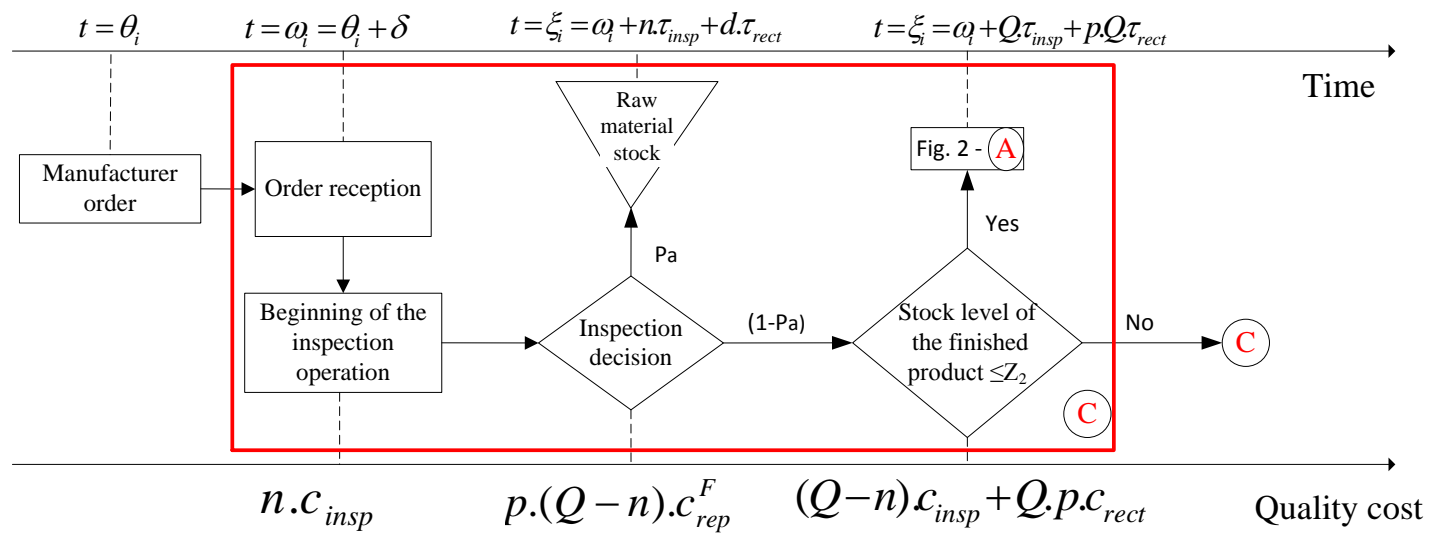

Total cost $=$ Supply cost + Quality cost + Raw material inventory cost + production cost + finished product inventory and backlog cost

Fig. 4: Hyb policy

According to the inspection policy, the $A O Q(t)$ equation is as follows:

$$
A O Q(t)=\left\{\begin{array}{l}
A O Q_{100 \%}(t)=\frac{\sum_{i=1 / a i=1}^{N(t)} p(Q-n)}{\sum_{i=1}^{N(t)} Q} \\
A O Q_{R e t}(t)=p \\
A O Q_{H y b}(t)=A O Q_{100 \%} \cdot \operatorname{Pr}\left(y(t) \leq Z_{2}\right)+A O Q_{R e t} .(1- \\
\\
\left.\operatorname{Pr}\left(y(t) \leq Z_{2}\right)\right)
\end{array}\right.
$$

where $N(t)$ represents the number of inspected lots at time $t, a^{i}=1$, if the $i^{t h}$ lot is accepted, and $a^{i}=0$ otherwise, and $\operatorname{Pr}\left(y(t) \leq Z_{2}\right)$ denotes the probability that the level of the finished product $y(t)$ is under a threshold $Z_{2}$.

To summarize, the different quality control policies break down as follows:

100\% policy: $\left\{\begin{array}{l}\text { Inspection limited to the sample } \mathrm{n}, \text { if } \mathrm{d} \leq \mathrm{c} . \\ \text { Full inspection and rectification operation, otherwise. }\end{array}\right.$

Ret policy: $\left\{\begin{array}{l}\text { Inspection limited to the sample } \mathrm{n}, \text { if } \mathrm{d} \leq \mathrm{c} . \\ \text { Return of the lot, otherwise. }\end{array}\right.$

Hyb policy: $\left\{\begin{array}{l}\text { Inspection limited to the sample } \mathrm{n}, \text { if } \mathrm{d} \leq \mathrm{c} . \\ \text { Otherwise, }\left\{\begin{array}{l}\bullet \text { Full inspection and rectification } \\ \text { operation, } \\ 12\end{array}\right.\end{array}\right.$ 


$$
\operatorname{if}\left(y(t) \leq Z_{2}\right)
$$

- Return of the lot, otherwise.

With constraint: $Z \geq Z_{2}, \mathrm{c} \geq 0$.

Where $\mathrm{Z}_{2}$ denotes the hedging level of finished production for the selection of quality decision.

Fig. 5 shows the dynamics of the raw material $x(t)$ and finished products $y(t)$ stock levels according to the joint production and supply control policy where the hybrid inspection policy is adopted. When the production system is available and $x(t)>0$, the raw material is transformed to finished products. Then, if $y(t)$ is below $Z$, the manufacturer produces at the maximal rate. When the production system is unavailable or $x(t)=0$, the production process is stopped until the repair of the system (after repair delay $\mathrm{R}$ ) or the introduction of a new order of raw materials to the raw materials stock (1). At the same time, when the raw material $x(t)$ level crosses the ordering point (2), the manufacturer orders a batch of raw materials from the supplier. This lot is delivered after a lead time $\delta$. Once the sample of size $\mathrm{n}$ is inspected after $(\mathrm{S}$ delay, the manufacturer decides to accept or to refuse this lot. If the lot is accepted, it is transferred to the final raw materials stock, at which point we note an increase in the $x(t)$ level 1 with $\mathrm{Q}$ items. Otherwise, if the lot is refused, the manufacturer checks the finished product level. If $y(t)$ is under $Z_{2}{ }^{3}$, the manufacturer performs a full inspection of the lot and reworks all non-confirming items with a (Q) delay. Otherwise ${ }^{4}$, the lot is returned to the supplier. In this case, the manufacturer must wait for another lead time $\delta$ until the new lot is delivered. 


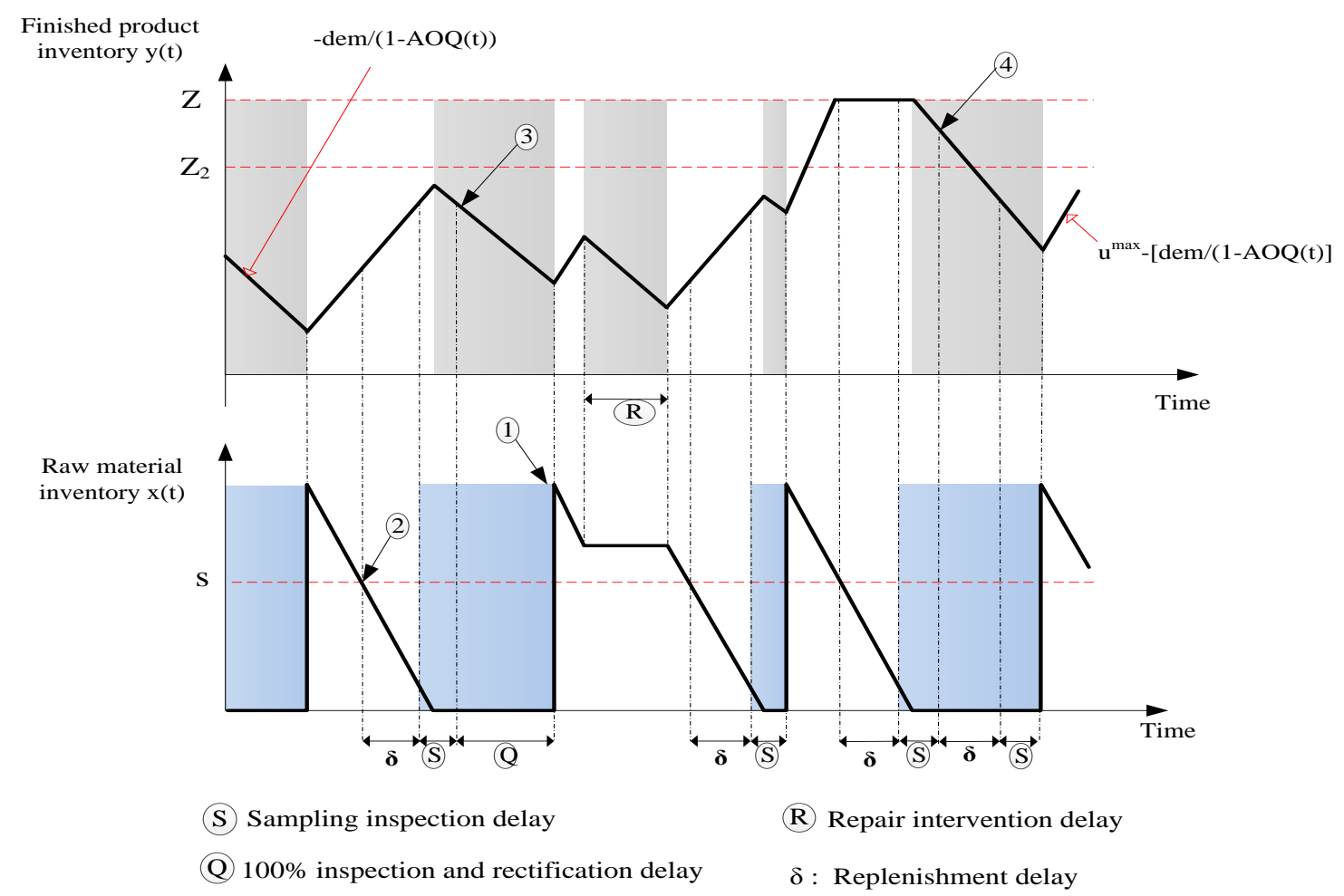

Fig. 5: Evolution of raw material inventory $x(t)$ and finished product inventory $y(t)$ under the joint production, supply and hybrid inspection policies

The supply chain system under consideration in this study is subject to random lead time and random availability of the production system. It is also subject to a high variability represented in the decisions made in the context of the inspection policies (determination of $\operatorname{Pr}\left(y(t) \leq Z_{2}\right)$ when the hybrid policy is applied or $\mathrm{N}_{\text {rej }}$ for the Ret policy). For these reasons, it is difficult to come up with an analytical solution. Therefore, we propose an experimental determination of the optimum control parameter $(s, Q, Z)$ or $\left(s, Q, Z, Z_{2}\right)$ that gives the best long-term expected total cost, which includes the ordering cost, the raw material cost, the raw material holding cost, the finished product holding/backlog costs, the cost of sampling, the costs of 100\% inspection and rectification (Case 100\% and $\mathrm{Hyb}$ policies) and the cost of replacing non-confirming finished products.

\section{Resolution approach}

The experimental approach adopted to solve the problem is a combination of simulation modelling, experimental design and surface methodology. The reader is referred to 
Rivera-Gómez et al. (2013) for more details. The main sequential steps of this approach are:

1. Development of a simulation model to describe the dynamics of the simultaneous production planning, replenishment and quality control problem by considering the control policy as input (Eqs. 3, 4 and 8).

2. Development of an appropriate experimental design with a minimal set of simulation runs. Data are then collected to perform a statistical analysis in order to determine the effects of the main factors, their quadratic effects, and their interactions (i.e., ANOVA analysis of variance) on the response (the cost).

3. Determination of the relationship between the incurred cost and the significant main factors and/or interactions using the Response Surface Methodology (RSM). From this estimated relation, known as the regression equation, the optimal values of the control policy parameters, called $\left(s^{*}, Q^{*}, Z^{*}\right)$ or $\left(s^{*}, Q^{*}, Z^{*}, Z_{2}{ }^{*}\right)$ and the optimal cost value are determined.

\section{Simulation model}

To reproduce the dynamic behaviour of the considered supply chain and decision process, a combined discrete/continuous model was developed using the SIMAN simulation language with $\mathrm{C}++$ subroutines (Pegden, 1995). The model was developed on ARENA simulation software. Using such a combined approach allows a reduction of the execution time and offers more flexibility to integrate the continuous tracking of system parameters (Lavoie et al., 2010). The simulation model in the case of a Hyb policy is presented in Fig. 6. 


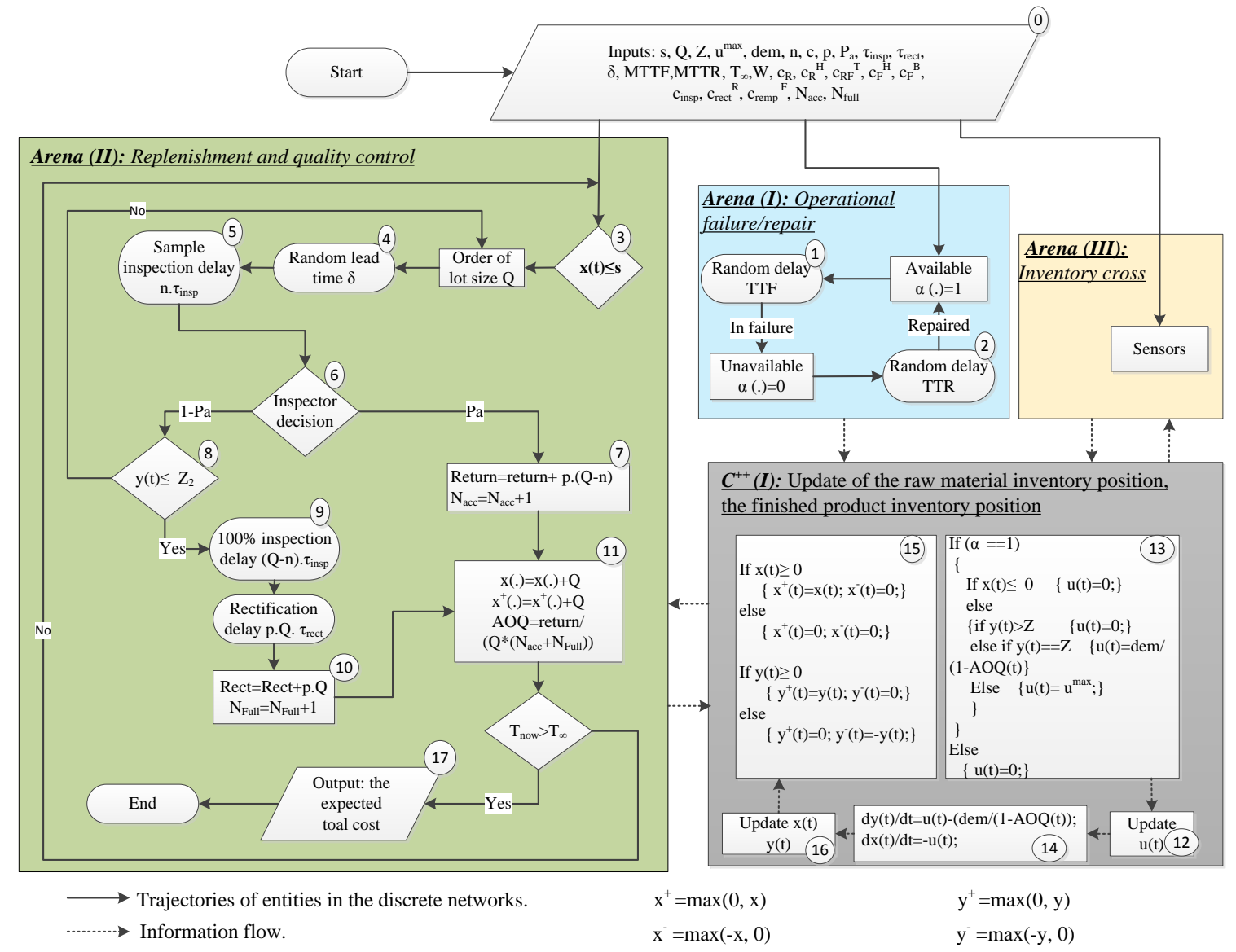

Fig. 6: Simulation block diagram (case of Hyb policy)

1. Block $(0)$ : This block initializes the values of the different parameters and variables of the problem, such as $\left(s, Q, Z, Z_{2}\right)$, production rates, the lead time, and inspection parameters. We also assign the simulation time $T_{\infty}$ at this step.

2. Arena (I): It models the operational failure and repair events. At the beginning of the simulation, the production process is set to available $(\alpha=1)$. Depending on the position of the entity, the manufacturer could be operational if the entity is held in the $T T F$ delay block ${ }^{(1)}$, or not operational, if it is in the TTR block ${ }^{2}$. We note that our simulation model is developed to accept any possible probability distribution.

3. Arena (II): It models the supply control policy (Eq. 4) ${ }^{3}$ and the quality control policy (Eq. 8). When the lot is delivered after a $\delta$ delay (4), a sample size is inspected ${ }^{5}$ and an inspection decision is taken ${ }^{6}$. Thanks to the probabilistic 
BRANCH block of SIMAN, only $P_{a}$ (Eq. 6) lot will be accepted. In this case ${ }^{7}$, the number of accepted lots and the cumulative returned quantity are updated by the discrete variables $N_{a c c}$ and Return, respectively. Otherwise, $\left(1-P_{a}\right)$ lots are rejected. If $y(t)$ is under $Z_{2}{ }^{8}$, the lot is submitted to $100 \%$ inspection and rectification operations ${ }^{9}$. At this point ${ }^{10}$, the number of lots subject to full inspection and the cumulative rectified quantity are updated by the discrete variables, $N_{F u l l}$ and Rect, respectively. When the lot is received in the raw materials stock ${ }^{11}$, the inventory level (Eq. 2) and the average outgoing quality $A O Q($.$) (Eq. 7) are updated.$

4. Arena (III): It continuously verifies whether or not the raw material or finished product inventory cross a threshold. It is presented by the DETECT block in SIMAN.

5. $C^{++}(\mathrm{I})$ : Using $\mathrm{C}$ language inserts, three operations are defined: First, an update of the production rate ${ }^{12}$ according to the control production policy ${ }^{13}$ defined by (Eq. 3). Secondly, there is the introduction of the dynamic of the production system ${ }^{14}$ defined by (Eq. 1). Then, the inventory position of raw material $x(t)$ and finished product $y(t)$ are integrated continuously ${ }^{15}$. Finally, we have an instantaneous update of the surplus and backlog levels of finished product and the surplus of the raw material by the routine ${ }^{16}$.

6. Finally, when the current time of the simulation $T_{\text {Now }}$ exceeds $T_{\infty}$, the simulation is stopped. Based on the different outputs ${ }^{17}$, the total cost is calculated.

\section{Experimental design and Response Surface Methodology}

This section applies the aforementioned approach to develop a regression equation aimed at determining the input parameters which affect the response, the relationship between the cost and significant factors, and finally, the optimal values of estimated factors. 


\subsection{Numerical example}

Our first case study considers the following values of the operational and cost parameters characterising the supply chain and inspection operations:

Table 1 Cost and production parameters

\begin{tabular}{|c|c|c|c|c|c|c|c|c|c|c|c|c|c|}
\hline Parameter & $u^{\max }$ & $\mathrm{dem}$ & $\mathrm{TTF}$ & $\mathrm{TTR}$ & $\mathrm{W}$ & $c_{R}$ & $c_{R}^{H}$ & $c_{R F}^{T}$ & $c_{\text {insp }}$ & $c_{F}^{H}$ & $c_{F}^{B}$ & $c_{\text {remp }}^{F}$ & $c_{\text {rect }}^{R}$ \\
\hline Values & 360 & 215 & $\operatorname{Expo}(15)$ & $\operatorname{Expo}(1.65)$ & 300 & 0.5 & 1 & 0.5 & 12 & 1 & 40 & 90 & 65 \\
\hline
\end{tabular}

Table 2 Inspection and delay parameters

\begin{tabular}{|c|c|c|c|c|c|c|c|}
\hline Parameter & $n$ & $c$ & $\% p$ & $\delta$ & $\tau_{\text {insp }}$ & $\tau_{\text {rect }}$ & $T_{\infty}$ \\
\hline Values & 125 & 3 & $2.5 \%$ & $\operatorname{Expo}(2)$ & $5.10^{-4}$ & 0.001 & 950,000 \\
\hline
\end{tabular}

Since we have four independent variables $\left(s, Q, Z, Z_{2}\right)$ for the Hyb Policy (three independent variables (s, Q, Z) for 100\% and Ret policies, respectively), a Face-Centered Central Composite design FCCCD $\left(2^{4}+8\right.$ star points +4 center points $)$ is selected $\left(3^{3}-\right.$ response surface design for the $100 \%$ and Ret policies, respectively). For each design, five replications were conducted, and therefore, $140(28 * 5)$ simulation runs were completed for the Hyb Policy $\left(135\left(3^{3} * 5\right)\right.$ simulation runs were completed for the $100 \%$ and Ret policies, respectively). Furthermore, the common random number technique (Law, 2007) was used to reduce the variability from one configuration to another.

Using a statistical software application such as STATGRAPHICS, a multi-factor analysis of the variance (ANOVA) of the simulated data was conducted. This analysis aimed to quantify the effect of the independents variables $(s, Q, Z)$ or $\left(s, Q, Z, Z_{2}\right)$ and their interactions on the dependent variable (the cost).

Based on a Pareto plot (Fig. 7), we found that all the factors of the different policies, their quadratic effect and their interaction are significant at the $95 \%$ level of significance. Furthermore, we noticed that all the $\mathrm{R}_{\mathrm{adj}}^{2}$ values (Fig. 7) of the proposed regression models were greater than $95 \%$. Over $95 \%$ of the total variability is thus explained by the models (Montgomery, 2013). 


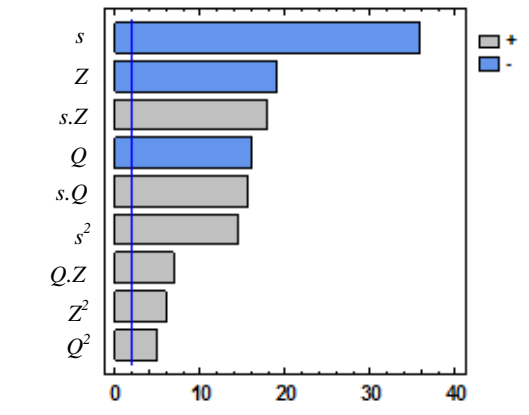

$\mathrm{R}_{\mathrm{ajs}}^{2}=95.39 \%$

(a): Ret

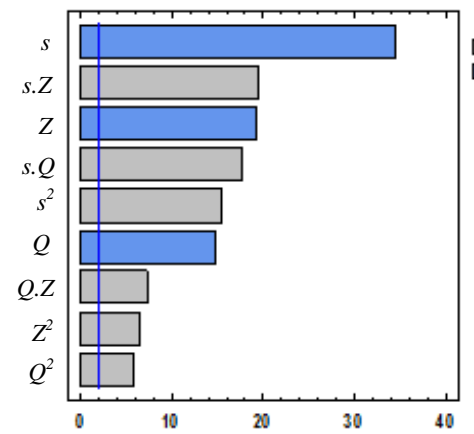

$\mathrm{R}_{\mathrm{ajs}}^{2}=95.48 \%$

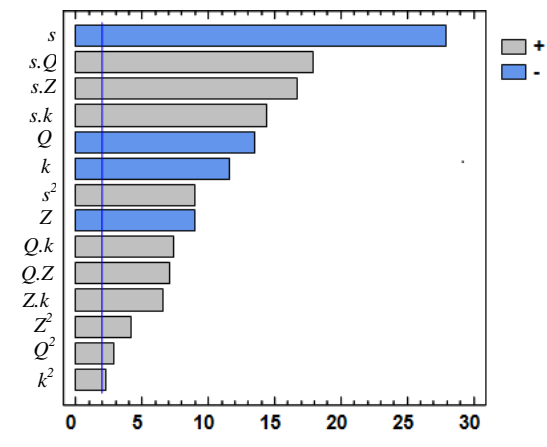

$\mathrm{R}_{\mathrm{ajs}}^{2}=96.19 \%$

(b): $100 \%$

(c): Hyb

Fig. 7: Standardized Pareto plot for the total cost $(\% p=2.5 \%)$

To verify the adequacy of the models, a residual analysis was conducted. The analysis consisted in testing the homogeneity of the variances and the residual normality using the residual versus predicted value plot and normal probability plot, respectively. We conclude that the models for the different policies are satisfactory. From STATSGRAPHICS, the second-order models of the total cost for each inspection policy are given by:

$$
\begin{aligned}
& \operatorname{Cost}_{\text {Ret }}(\mathrm{s}, \mathrm{Q}, \mathrm{Z})=38003.3-16.474 . \mathrm{s}-9.10348 . \mathrm{Q}-9.00821 . \mathrm{Z}+ \\
& \text { 0.00240846. } \mathrm{s}^{2}+\text { 0.0019288.s. } \mathrm{Q}+\text { 0.00209273.s. Z + } \\
& \text { 0.000915866. } Q^{2}+0.000850717 . Q . Z+0.00099188 . Z^{2} \text {. } \\
& \operatorname{Cost}_{100 \%}(s, Q, Z)=25372.3-15.9824 . s-8.83754 . Q-7.45347 . Z+ \\
& \text { 0.00358277. } s^{2}+0.00297361 . s . Q+0.0026577 . s . Z+0.00141921 . Q^{2}+ \\
& 0.00102811 . Q . Z++0.00105296 . Z^{2} \text {. } \\
& \operatorname{Cost}_{\mathrm{Hyb}}(\mathrm{s}, \mathrm{Q}, Z, \mathrm{k})=25173.4-10.8384 . \mathrm{s}-5.66342 . \mathrm{Q}-8.17662 . Z \text { - } \\
& \text { 6525.83. } k+0.00180302 . \mathrm{s}^{2}+\text { 0.00146689.s. } \mathrm{Q}+\text { 0.00165998.s.Z }+ \\
& \text { 1.66332.s. } \mathrm{k}+0.000591633 . \mathrm{Q}^{2}+0.000716081 . \mathrm{Q} . Z+0.871479 . \mathrm{Q} . \mathrm{k}+ \\
& 0.00128123 . Z^{2}+0.948431 . Z \cdot \mathrm{k}+946.265 . \mathrm{k}^{2} \text {. }
\end{aligned}
$$

Where $k=Z_{2} / Z$ (To make sure that $Z_{2} \leq \mathrm{Z}$ ).

Based on the relationship between the dependent (the cost) and the independent variables $(s, Q, Z)$ or $\left(s, Q, Z, Z_{2}\right)$, in Fig. 8, we present the projection of the response surface of the 
cost function in a two-dimensional plan. Fig. 8 shows the parameter corresponding to the minimum total cost for the three policies: $s^{*}=1744.35, Q^{*}=2346$ and $Z^{*}=1694.56$ (Fig. 8.(a)); $s^{*}=1091.1, Q^{*}=1442$ and $Z^{*}=1458.27$ (Fig. 8.(b)) and $s^{*}=1166.13, Q^{*}=$ $1764 Z^{*}=1652.83$ and $\mathrm{Z}_{2}^{*}=1293.82$ (Fig. 8.(c)).
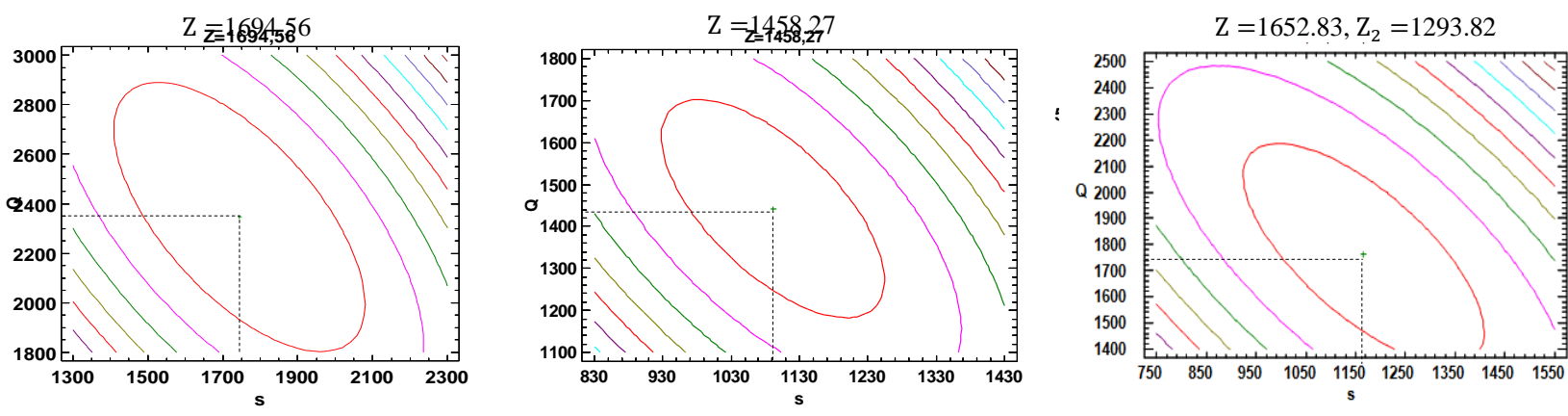

(c): Hyb

Fig. 8: Contours of Estimated Response Surface

Furthermore, to confirm the validity of our models, we established the confidence interval at 95\% using (Eq.13). By running $\mathrm{h}=20$ extra replications using optimal parameters, we noticed that the minimum cost of each inspection policy is within the confidence interval (Table 3).

$$
\bar{C}^{*}(h) \pm t_{\frac{\alpha}{2}, \boldsymbol{h - 1}} \cdot \sqrt{S^{2}(h) / h}
$$

where $\bar{C}^{*}$ is the average optimal cost, $S$ the sample standard deviation and $(1-\alpha)$ the confidence level.

As shown in Table 3, these results illustrate the superiority of the Hyb policy as compared to the Ret and $100 \%$ policies, which help ensure a lower total cost. This is due to its structure, with which the decision maker coordinates the inspection decision with the production and replenishment decisions, depending on the finished product stock level. To illustrate the robustness of this resolution approach for ranges of systems parameters, a sensitivity analysis will be performed.

Table 3 Confidence interval and optimal parameters and cost results

\begin{tabular}{|l|l|l|l|}
\hline Policies & Optimal Parameters & Optimal Cost & CI (95\%) \\
\hline
\end{tabular}




\begin{tabular}{|c|c|c|c|c|c|c|}
\hline & $s^{*}$ & $Q^{*}$ & $Z^{*}$ & $\mathrm{Z}_{2}{ }^{*}$ & & \\
\hline Ret & 1744.35 & 2346 & 1694.56 & - & 5323.41 & {$[5312.33,5387.58]$} \\
\hline $100 \%$ & 1091.1 & 1442 & 1458.27 & - & 4845.85 & {$[4828.88,4875.81]$} \\
\hline Hyb & 1166.13 & 1764 & 1652.83 & 1293.82 & 4547.58 & {$[4539.49,4575.16]$} \\
\hline
\end{tabular}

Furthermore, since a sampling plan was adopted, we compared these policies to a full control policy (Full). In fact, the full policy is a particular case of the sampling policy where the probability of acceptance $P_{\boldsymbol{a}}=0$. We found that the $\operatorname{Cost}_{\mathrm{Full}}^{*}=6155.86$. Based on this result, we can conclude the advantage of a sampling plan control policy as compared to full policy.

\subsection{Sensitivity analysis}

Sensitivity analyses are necessary to ensure a full understanding of the effect of a given parameter variation on the entire system and to make sure that all variations make sense. In this study, we concentrated our efforts on operational parameters judged the most appropriate. Hence, the inspection plan; the replenishment delay; positive inventory, backlog, ordering and inspection costs are considered in conducting the sensitivity analysis.

The results obtained (Table 4) show the impact of this variation on the optimal control parameters $\left(s^{*}, Q^{*}, Z^{*}, Z_{2}^{*}\right)$ when a Hyb policy is considered.

\subsubsection{Case 1: Variation of the ordering cost $\mathrm{W}$}

When the cost $\mathrm{W}$ increases, the decision maker had to order a larger lot size $\left(\mathrm{Q}^{*}\right.$ increases), but less frequently ( $\mathrm{s}^{*}$ decreases). Indeed, by ordering higher quantities, the system keeps a higher level of raw materials (R.M), allowing on the one hand it to decrease the finished product (F.P.) threshold $\mathrm{Z}^{*}$, and on the other, to promote return decisions $\left(\mathrm{Z}_{2}{ }^{*}\right.$ decreases) in order to avoid high inventory costs. When the cost W decreases, we note an opposite variation. 


\subsubsection{Case 2: Variation of the raw material holding $\operatorname{cost} \mathrm{c}_{\mathrm{R}}^{\mathrm{H}}$}

When the $c_{R}^{H}$ cost increases, the manager had to decrease the raw material stock level by ordering less frequently ( $s^{*}$ decreases) in order to reduce inventory costs. In this situation, the manufacturer had to promote more $100 \%$ inspection decisions on refused lots than decisions to return to the supplier $\left(\mathrm{Z}_{2}{ }^{*}\right.$ increases $)$. Consequently, $\mathrm{Q}^{*}$ decreases to reduce total inspection cost. At the same time, $Z^{*}$ increases. In fact, this variation aimed to increase the transformation of R.M. into the final product (F.P.) to meet a continuous demand and increase the stock-out frequency of R.M. When the $c_{R}^{H}$ cost decreases, we note an opposite variation of the optimal parameters.

\subsubsection{Case 3: Variation of the inspection cost $c_{\text {insp }}$}

When the $c_{\text {insp }}$ cost increases, the manager had to reduce the total inspection cost, which included sampling and $100 \%$ inspection costs. For this reason, the manufacturer had to promote return decisions $\left(\mathrm{Z}_{2}{ }^{*}\right.$ decreases $)$. At the same time, $s^{*}$ and $\mathrm{Q}^{*}$ increase to ensure the presence of enough R.M, and $Z^{*}$ increases to ensure the presence of enough F.P. When the $c_{\text {insp }}$ cost decreases, we note an opposite variation of the optimal parameters.

\subsubsection{Case 4: variation of the finished product holding $\cos t \mathrm{c}_{\mathrm{F}}^{\mathrm{H}}$}

When the $\mathrm{c}_{\mathrm{F}}^{\mathrm{H}}$ cost increases, the optimal threshold $\mathrm{Z}^{*}$ decreases in order to reduce the inventory costs. By keeping a lower level of F.P., the manufacturer had to ensure the continuity of the production process by reducing the stock-out frequency of R.M ( $s^{*}$ and $\mathrm{Q}^{*}$ increase). At the same time, the manufacturer promoted the return option $\left(\mathrm{Z}_{2}{ }^{*}\right.$ decreases) to avoid high R.M holding costs. When the $\mathrm{c}_{\mathrm{F}}^{\mathrm{H}}$ cost decreases, we note an opposite variation of the optimal parameters. 
Table 4 Sensitivity analysis data and results of the Hyb policy

\begin{tabular}{|c|c|c|c|c|c|c|c|c|c|c|}
\hline \multirow{2}{*}{ Cases } & \multirow{2}{*}{ Parameter } & \multirow{2}{*}{ Variation } & \multicolumn{4}{|c|}{ Optimal Parameters } & \multirow{2}{*}{$\operatorname{Cost}_{\mathrm{Hyb}}^{*}$} & \multirow{2}{*}{$\operatorname{Cost}_{100 \%}^{*}$} & \multirow{2}{*}{$\operatorname{Cost}_{\text {Ret }}^{*}$} & \multirow{2}{*}{$\begin{array}{l}\text { Impact on } \\
\text { Hyb policy }\end{array}$} \\
\hline & & & $\mathrm{s}^{*}$ & $\mathrm{Q}^{*}$ & $\mathrm{Z}^{*}$ & $\mathrm{Z}_{2}^{*}$ & & & & \\
\hline Base & - & - & 1166.13 & 1764 & 1652.83 & 1293.82 & 4547.58 & 4845.85 & 5323.41 & - \\
\hline \multirow{2}{*}{1} & \multirow{2}{*}{ W } & 500 & 1158.08 & 1789 & 1651.78 & 1285.69 & 4572.16 & 4875.95 & 5342.14 & $\mathrm{~s}^{*} \downarrow \mathrm{Q}^{* \uparrow} \mathrm{Z}^{*} \downarrow \mathrm{Z}_{2}^{*} \downarrow \operatorname{Cost}^{*} \uparrow$ \\
\hline & & 100 & 1175.18 & 1737 & 1653.56 & 1300.9 & 4522.49 & 4815.47 & 5304.68 & $\mathrm{~s}^{* \uparrow} \mathrm{Q}^{*} \downarrow \mathrm{Z}^{*} \uparrow \mathrm{Z}_{2}^{*} \uparrow \operatorname{Cos} \mathrm{t}^{*} \downarrow$ \\
\hline \multirow{2}{*}{2} & \multirow{2}{*}{$c_{R}^{H}$} & 1.35 & 1064.39 & 1634 & 1728.41 & 1487.57 & 4999.30 & 5282.29 & 6058.25 & $\mathrm{~s}^{*} \downarrow \mathrm{Q}^{*} \downarrow \mathrm{Z}^{*} \uparrow \mathrm{Z}_{2}^{*} \uparrow \operatorname{Cost}^{*} \uparrow$ \\
\hline & & 0.65 & 1289.16 & 896 & 1574.3 & 1059.63 & 4041.20 & 4378.00 & 4540.69 & $\mathrm{~s}^{* \uparrow} \mathrm{Q}^{* \uparrow} \mathrm{Z}^{*} \downarrow \mathrm{Z}_{2}^{*} \downarrow$ Cost* $\downarrow$ \\
\hline \multirow{2}{*}{3} & \multirow{2}{*}{$c_{\text {insp }}$} & 24 & 1273.15 & 2153 & 1668.98 & 834.25 & 5017.45 & 5978.17 & 5546.31 & $\mathrm{~s}^{* \uparrow} \mathrm{Q}^{*} \uparrow \mathrm{Z}^{*} \uparrow \mathrm{Z}_{2}^{*} \downarrow \operatorname{Cost} \mathrm{C}^{*} \uparrow$ \\
\hline & & 6 & 1149.09 & 1596 & 1643.35 & 1486.41 & 4232.37 & 4277.37 & 5208.65 & $\mathrm{~s}^{*} \downarrow \mathrm{Q}^{*} \downarrow \mathrm{Z}^{*} \downarrow \mathrm{Z}_{2}^{*} \uparrow \operatorname{Cost}^{*} \uparrow$ \\
\hline \multirow{2}{*}{4} & \multirow{2}{*}{$\mathrm{c}_{\mathrm{F}}^{\mathrm{H}}$} & 1.1 & 1181.9 & 1768 & 1604.07 & 1255.14 & 4687.77 & 4970.90 & 5470.07 & $\mathrm{~s}^{* \uparrow} \mathrm{Q}^{*} \uparrow \mathrm{Z}^{*} \downarrow \mathrm{Z}_{2}^{*} \downarrow \operatorname{Cost}^{*} \uparrow$ \\
\hline & & 0.9 & 1151.07 & 1759 & 1700.42 & 1333.90 & 4403.11 & 4713.29 & 5168.78 & $\mathrm{~s}^{*} \downarrow \mathrm{Q}^{*} \downarrow \mathrm{Z}^{*} \uparrow \mathrm{Z}_{2}^{*} \uparrow \operatorname{Cost}^{*} \downarrow$ \\
\hline \multirow{2}{*}{5} & \multirow{2}{*}{$\mathrm{c}_{\mathrm{F}}^{\mathrm{B}}$} & 52 & 1175.05 & 1728 & 1709.75 & 1482.70 & 4668.22 & 4971.91 & 5506.79 & $\mathrm{~s}^{* \uparrow} \mathrm{Q}^{*} \downarrow \mathrm{Z}^{*} \uparrow \mathrm{Z}_{2}^{*} \uparrow \operatorname{Cos} \mathrm{C}^{*} \uparrow$ \\
\hline & & 28 & 1120.01 & 1788 & 1552.97 & 1109.01 & 4384.02 & 4673.71 & 5090.58 & $\mathrm{~s}^{*} \downarrow \mathrm{Q}^{*} \uparrow \mathrm{Z}^{*} \downarrow \mathrm{Z}_{2}^{*} \downarrow \operatorname{Cost}^{*} \downarrow$ \\
\hline \multirow{2}{*}{6} & \multirow{2}{*}{$\% p$} & $3 \%$ & 1287.54 & 1685 & 1695.92 & 1368.84 & 4944.30 & 5252.64 & 6633.85 & $\mathrm{~s}^{* \uparrow} \mathrm{Q}^{*} \downarrow \mathrm{Z}^{*} \uparrow \mathrm{Z}_{2}^{*} \uparrow \operatorname{Cost}^{*} \uparrow$ \\
\hline & & $2 \%$ & 1103.87 & 1866 & 1525.72 & 1149.88 & 4285.15 & 4404.27 & 4548.25 & $\mathrm{~s}^{*} \downarrow \mathrm{Q}^{*} \uparrow \mathrm{Z}^{*} \downarrow \mathrm{Z}_{2}^{*} \downarrow \operatorname{Cost}^{*} \downarrow$ \\
\hline \multirow{2}{*}{7} & \multirow{2}{*}{$\mathrm{c}$} & 4 & 1123.19 & 1595 & 1545.93 & 1089.26 & 4212.46 & 4448.39 & 4557.42 & $\mathrm{~s}^{*} \downarrow \mathrm{Q}^{*} \downarrow \mathrm{Z}^{*} \downarrow \mathrm{Z}_{2}^{*} \downarrow \operatorname{Cost}^{*} \downarrow$ \\
\hline & & 2 & 1261.11 & 1827 & 1826.86 & 1518.91 & 5034.59 & 5339.85 & 6762.16 & $\mathrm{~s}^{*} \uparrow \mathrm{Q}^{*} \uparrow \mathrm{Z}^{*} \uparrow \mathrm{Z}_{2}^{*} \uparrow \operatorname{Cost}^{*} \uparrow$ \\
\hline \multirow{2}{*}{8} & \multirow{2}{*}{$\delta$} & $\operatorname{Expo}(2.5)$ & 1526.63 & 2030 & 1756.45 & 1477.79 & 5039.55 & 5291.51 & 6196.43 & $\mathrm{~s}^{* \uparrow} \mathrm{Q}^{*} \uparrow \mathrm{Z}^{*} \uparrow \mathrm{Z}_{2}^{*} \uparrow \operatorname{Cost}^{*} \uparrow$ \\
\hline & & $\operatorname{Expo(0.75)}$ & 400.09 & 1347 & 1297.73 & 449.413 & 3509.54 & 4004.74 & 3646.33 & $\mathrm{~s}^{*} \downarrow \mathrm{Q}^{*} \downarrow \mathrm{Z}^{*} \downarrow \mathrm{Z}_{2}^{*} \downarrow \mathrm{Cost}^{*} \downarrow$ \\
\hline
\end{tabular}




\subsubsection{Case 5: variation of the finished product backlog $\operatorname{cost} \mathrm{c}_{\mathrm{F}}^{\mathrm{B}}$}

When the $\mathrm{c}_{\mathrm{F}}^{\mathrm{B}}$ cost increases, the manufacturer increases the $Z^{*}$ in order to ensure enough F.P. and meet customer demand. In this situation, the manufacturer had to ensure a higher R.M. stock level by promoting $100 \%$ inspection operations if the inspected lot was rejected $\left(\mathrm{Z}_{2}{ }^{*}\right.$ increased $)$. At the same time, we note the increase of the number of ordered lot ( $\mathrm{s}^{*}$ increased) balanced by a decrease of $\mathrm{Q}^{*}$. In fact, this variation aimed to decrease

the total inspection costs. With the lower $\mathrm{c}_{\mathrm{F}}^{\mathrm{B}} \operatorname{cost}$, we note an opposite variation of the different optimal parameters.

\subsubsection{Case 6: Variation of the proportion of non-conforming raw material \%p}

When the proportion of non-conforming R.M (\%p) increases, the acceptance probability $\mathrm{Pa}$ decreases, and more received lots are refused. Therefore, the manufacturer had to reduce the frequency of lot returns to the supplier $\left(\mathrm{Z}_{2}{ }^{*}\right.$ increased $)$, increases the number of ordered lots ( $\mathrm{s}^{*}$ increases) and increases the F.P threshold level $\mathrm{Z}^{*}$. In this situation, $\mathrm{Q}^{*}$ decreased to reduce the total inspection costs. In the opposite case (\%p decreases), we have an opposite variation of the parameters.

\subsubsection{Case 7: Variation of the acceptance number $\mathrm{c}$}

When the acceptance number c decreases, the acceptance probability Pa decreases. In this situation, the decision to refuse an inspected lot increases and thus the ordering point $\mathrm{s}^{*}$ and the lot size $\mathrm{Q}^{*}$ increase. At the same time, $\mathrm{Z}_{2}{ }^{*}$ increases to reduce the number of return of the refused lot and $\mathrm{Z}^{*}$ increases to tackle the R.M. stock-out frequency and the demand. In the opposite case (c increases), we have an opposite variation of the optimal parameters.

\subsubsection{Case 8: Variation of the replenishment delay $\delta$}

The increase in the replenishment delay encourages the manufacturer to promote $100 \%$ inspection decisions over return decisions $\left(\mathrm{Z}_{2}{ }^{*}\right.$ increases). In this situation, the manufacturer increases the order frequency ( $s^{*}$ increases) and the lot size $\mathrm{Q}^{*}$ to ensure the presence of enough raw materials. In addition $Z^{*}$ increases to ensure the presence of 
enough F.P. to meet customer demand. In the opposite case (lead time decreases), we have an opposite variation of the optimal parameters.

In conclusion, the different results obtained in this analysis confirm the robustness of the Hyb policy. This sensitivity analysis was also performed on both $100 \%$ and Ret policies to confirm their robustness. During this analysis, we made two main observations. On the one hand, for the different parameters of Table 4, Cost ${ }_{\mathrm{Hyb}}^{*}$ is always lower than the optimal total cost of both the Ret and $100 \%$ policies. On the other hand, contrary to the conclusion of the Table 3, the Ret policy could be more preferred than the $100 \%$ policy (Table 4, case 3: $c_{i n s p}=24 \$ / u$ and case $8: \delta=$ Expo (0.75)/day). By contrast, the Hyb policy remains superior. Therefore, under which condition is the Ret policy better than the $100 \%$ policy and vice-versa? Is the Hyb policy always better than the $100 \%$ and Ret policies? To answer these questions, we conduct a detailed comparative study between the three policies in the next section.

\section{Comparative study of Ret, $100 \%$ and Hyb policies}

In this section, we compare the Ret, $100 \%$ and $\mathrm{Hyb}$ policies for a system-wide range of parameters, namely, $\% p, \delta, \mathrm{c}_{\mathrm{insp}}$ and $\mathrm{c}$. This variation was conducted under similar conditions (simulation parameters, cost variation and inspection plan).

To confirm the different observations presented in Fig. 9 to Fig. 16, a Student's t-test was performed. Generally, the confidence interval (CI) of $\bar{C}_{1}^{*}-\bar{C}_{2}^{*}$ for two distinct policies (1) and (2) is determined by Eq. (14) (Banks, 2009).

$$
\begin{array}{rl}
\bar{C}_{1}^{*}-\bar{C}_{2}^{*}-t_{\frac{\alpha}{2}, h-1} & s \cdot e\left(\bar{C}_{1}^{*}-\bar{C}_{2}^{*}\right) \leq C_{1}^{*}-C_{2}^{*} \\
\leq & \bar{C}_{1}^{*}-\bar{C}_{2}^{*}+t_{\overline{2}, \boldsymbol{h}-1} \text { s.e }\left(\bar{C}_{1}^{*}-\bar{C}_{2}^{*}\right)
\end{array}
$$

Where: h: Number of replications $(h=20)$.

$\bar{C}_{1}^{*}\left(\right.$ resp. $\left.\bar{C}_{2}^{*}\right)$ : Average total cost under the first (resp. second) policy.

$t_{\frac{\alpha}{2}, h-1}$ : The student coefficient function of parameters $h$ and $\alpha$, where $(1-\alpha)$ is the confidence level (set at 95\%). 
s.e $\left(\bar{C}_{1}^{*}-\bar{C}_{2}^{*}\right)=\sqrt{S_{D}^{2} / h}$ : The Standard error.

To improve the readability of the text, we will use $\mathrm{CI}_{\mathrm{i}-\mathrm{j}}$ to designate the confidence interval of $\overline{\mathrm{C}}_{\mathrm{i}}^{*}-\overline{\mathrm{C}}_{\mathrm{j}}^{*}$, where $\overline{\mathrm{C}}_{\mathrm{i}}^{*}$ and $\overline{\mathrm{C}}_{\mathrm{j}}^{*}$ are the Average total cost for policy $i$ and $j$, respectively.

\subsection{Effect of the proportion of non-conforming \%p variation}

According to the base case Fig. 9, we note that:

- For $\%$ p $\leq 1.5 \%$ : The difference between the costs of the three different inspection policies is not significant $\left(\overline{\mathrm{C}}_{\mathrm{Hyb}}^{*} \simeq \overline{\mathrm{C}}_{100 \%}^{*} \simeq \overline{\mathrm{C}}_{\mathrm{Ret}}^{*}\right)$. To confirm this observation, we found that the zero $(0)$ is inside the CI $(95 \%)\left(C I_{\text {Ret-100\% }}=[-6.46,18.35]\right.$, $\left.C I_{100 \%-H y b}=[-26.99,6.68], C I_{R e t-H y b}=[-14.65,6.23]\right)$.

- For $\%$ p $>1.5 \%$ : The Hyb policy is the most preferred one given that it offers the least optimal cost. In fact, the determination of the confidence interval for case 2 shows that all the $\mathrm{CI}(95 \%)>0$ and that $\overline{\mathrm{C}}_{\mathrm{Hyb}}^{*}<\overline{\mathrm{C}}_{100 \%}^{*}<\overline{\mathrm{C}}_{\operatorname{Ret}}^{*}, \quad\left(C I_{\text {Ret }-100 \%}=\right.$ $\left.[279.46,331.3], C I_{100 \%-H y b}=[272.35,298.95], C I_{R e t-H y b}=[565.79,616.27]\right)$.

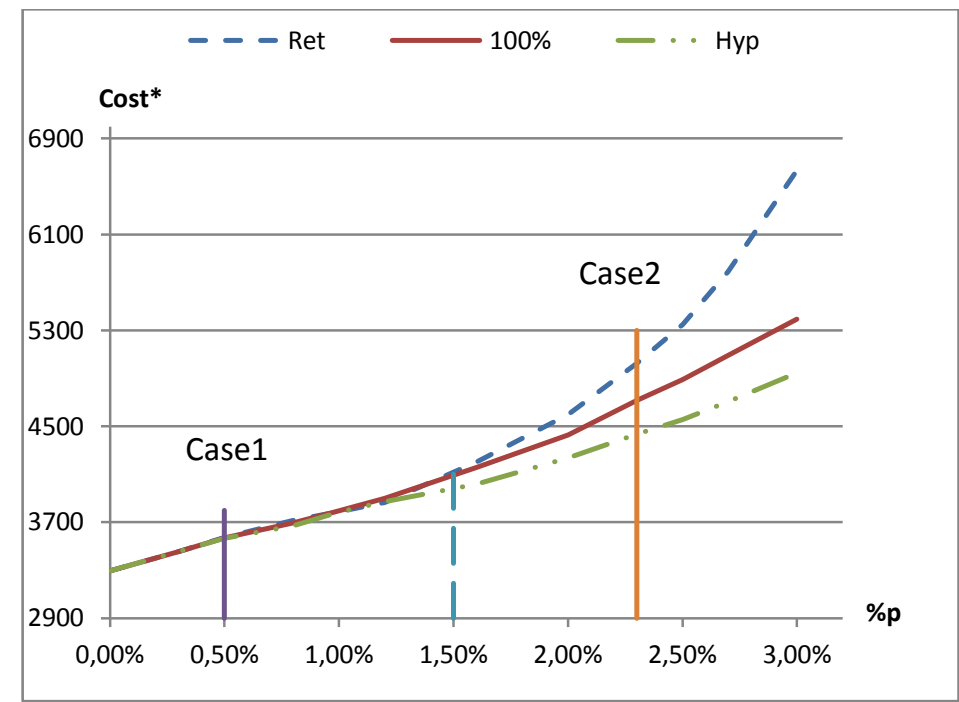

Fig. 9: Cost $^{*}=f(\% p)$, case $\delta=\operatorname{Expo}(2), \mathrm{c}=3, \mathrm{c}_{\mathrm{insp}}=12 \$ / u$. 


\subsection{Effect of the replenishment delay $\delta$ variation}

Despite the variation of the lead time $\delta$ (Fig. 10 and Fig. 11), the cost curves present two similar variations as those of Fig. 9. First, for $\% p \leq 0.45 \%$ (Fig. 10) and $\% p \leq 0.6 \%$ (Fig. 11), $\overline{\mathrm{C}}_{\mathrm{Hyb}}^{*} \simeq \overline{\mathrm{C}}_{100 \%}^{*} \simeq \overline{\mathrm{C}}_{\text {Ret }}^{*}$; second, for \%p $>0.45 \%$ (Fig. 10) and \%p $>0.6 \%$ (Fig. 11), the Hyb policy is more preferred than the $100 \%$ policy (case 3, $C I_{100 \%-H y b}=[158.24$, 189.27] $>0$ and case $\left.4, C I_{100 \%-H y b}=[573.53,608.62]\right)$. Regarding the comparison between the Hyb and Ret policies, case 3 (Fig. 10) shows that $\overline{\mathrm{C}}_{\mathrm{Hyb}}^{*}<\overline{\mathrm{C}}_{\mathrm{Ret}}^{*}$. However, in an extreme case where $\delta=0$ (Fig. 11), the Hyb policy coincides with the Ret policy $\left(C I_{\text {Ret-Hyb }}=[-27.7,12.36]\right)$, which is intuitively predictable.

Unlike Fig. 9, Fig. 10 presents different curve positions for the Ret and 100\% policies. We note that:

- For $0.45 \%<\% p<2.15 \%$ : $\quad \overline{\mathrm{C}}_{\mathrm{Ret}}^{*}<\overline{\mathrm{C}}_{100 \%}^{*}$ (case 3, $\mathrm{CI}_{\text {Ret-100\% }}=[-93.24$, $59.24]<0$ ). In fact, when the lead time and the non-conforming percentage are not too large, it is more appropriate to return the refused lot to the supplier than to perform a $100 \%$ inspection in order to avoid additional inspection and rectification costs. This trend holds up to a certain value of $\% p=2.15 \%$, where the Ret policy $=$ the $100 \%$ policy.

- For $\% p>2.15 \%: \overline{\mathrm{C}}_{100 \%}^{*}<\overline{\mathrm{C}}_{\mathrm{Ret}}^{*}$. In response to receiving a lot with a higher percentage of non-conforming items, the frequency of accepting a lot decreases by reducing the acceptance probability $\mathrm{P}_{\mathrm{a}}$. In this situation, it is more preferred to perform a $100 \%$ inspection than return the lot, in order to increase the availability of raw materials, which reduces the risk of finished product backlogs. 


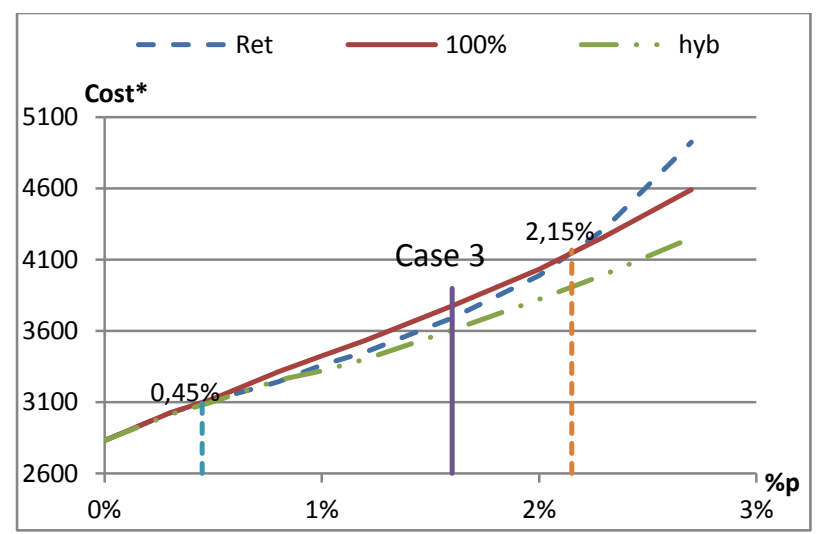

Fig. 10: Cost $^{*}=\mathrm{f}(\% \mathrm{p})$, case $\delta=\operatorname{Expo}(\mathbf{1 . 5}), \mathrm{c}=3$, $\mathrm{c}_{\text {insp }}=12 \$ / u$

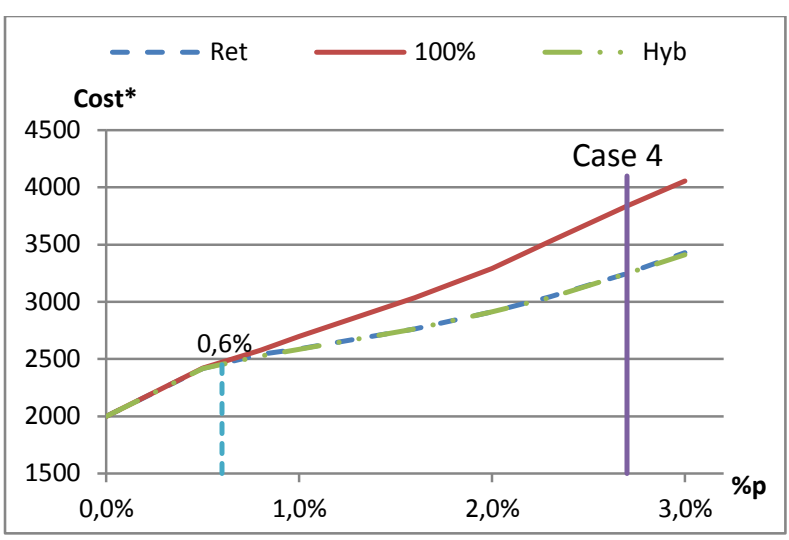

Fig. 11: Cost $^{*}=\mathrm{f}(\% \mathrm{p})$, case $\delta=\mathbf{0}, \mathrm{c}=3, \mathrm{c}_{\mathrm{insp}}=12 \$ / u$

\subsection{Effect of inspection cost $c_{\text {insp }}$ variation}

Despite the variation of the inspection cost $c_{\text {insp }}$ presented in Fig. 12, Fig. 13 and Fig. 14, the cost curves present two similar variations as those in Fig. 9. First, for $\% p \leq 0.65 \%$ (Fig. 12), $\%$ p $\leq 0.7 \%$ (Fig. 13) and $\% \mathrm{p} \leq 0.84 \%$ (Fig. 14), $\overline{\mathrm{C}}_{\mathrm{Hyb}}^{*} \simeq \overline{\mathrm{C}}_{100 \%}^{*} \simeq \overline{\mathrm{C}}_{\text {Ret }}^{*}$. Second, for $\% p>0.65 \%$ (Fig. 12), \%p $>0.7 \%$ (Fig. 13) and \%p $>0.84 \%$ (Fig. 14), the Hyb policy is more preferred than the Ret policy. In fact, the determination of the confidence interval for case 5 (Fig. 12) shows $C I_{\text {Ret-Hyb }}=[565.79,616.27]>0$ (same result in cases 6 (Fig. 13) and 7 (Fig. 14)). Regarding the comparison between the Hyb and $100 \%$ policies, case 5 (Fig. 12) and case 6 (Fig. 13) show that the Hyb policy is always better than $100 \%\left(\overline{\mathrm{C}}_{\mathrm{Hyb}}^{*}<\overline{\mathrm{C}}_{100 \%}^{*}\right)$. However, in an extreme case where $\mathrm{c}_{\text {insp }}=0$ (Fig. 14), the Hyb policy curve coincides with that of the $100 \%$ policy (case 7, $\left.C I_{100 \%-H y b}=[-8.59,10.53]\right)$, which is intuitively predictable.

Unlike Fig. 9, Fig. 12 and Fig. 13 present different curve positions of the Ret and 100\% policies. We note that:

- For $0.65 \%<\%$ p $<2.42 \%$ (Fig. 12) and $0.7 \%<\%$ p $<2.73 \%$ (Fig. 13): $\overline{\mathrm{C}}_{\text {Ret }}^{*}<$ $\overline{\mathrm{C}}_{100 \%}^{*}$. To confirm this observation, we found that $\mathrm{CI}_{\text {Ret-100\% }}=[-134.84,-105.59]$ $<0$ for case 5 (Fig. 12) and $\mathrm{CI}_{\text {Ret }-100 \%}=[-340.56,-295.48]<0$ for case 6 (Fig. 13). In this case, performing a full inspection would lead to higher inspection costs, and returning a refused lot to the supplier becomes a more economical decision. This 
trend holds up to a certain value of $\% p=2.42 \%$ (Fig. 12) and $\% p=2.73 \%$ (Fig. 13) where the Ret policy $=$ the $100 \%$ policy. It is preferred to note that when the $\mathrm{c}_{\text {insp }}$ increases, the range of the $\% \mathrm{p}$ value for which the Ret policy is superior to the $100 \%$ policy increases.

- $\quad$ For $\% p>2.42 \%$ (Fig. 12) and \%p $>2.73 \%$ (Fig. 13): $\overline{\mathrm{C}}_{100 \%}^{*}<\overline{\mathrm{C}}_{\text {Ret }}^{*}$. Even if the inspection cost is high, it would be more preferred to perform a $100 \%$ inspection. Such a decision reduces the risk of finished product backlogs by increasing the availability of raw materials when the acceptance probability $\mathrm{P}_{\mathrm{a}}$ decreases.

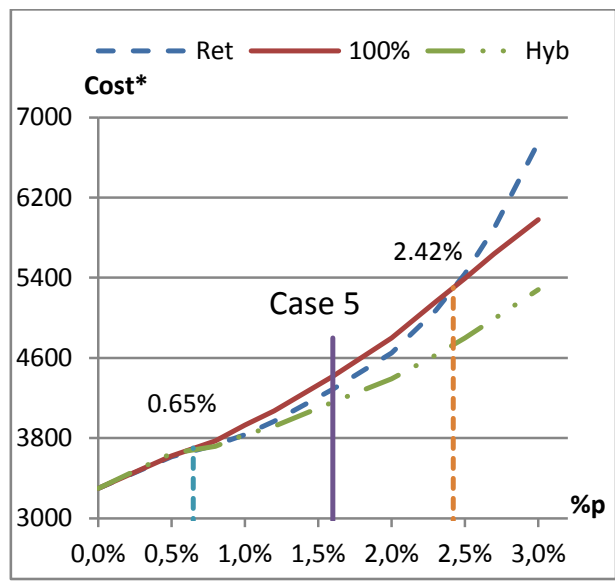

Fig. 12: Cost $^{*}=\mathrm{f}(\% \mathrm{p})$, case $\delta=\operatorname{Expo}(2)$, $\mathrm{c}=\mathbf{3}, \mathrm{c}_{\text {insp }}=18 \$ / u$

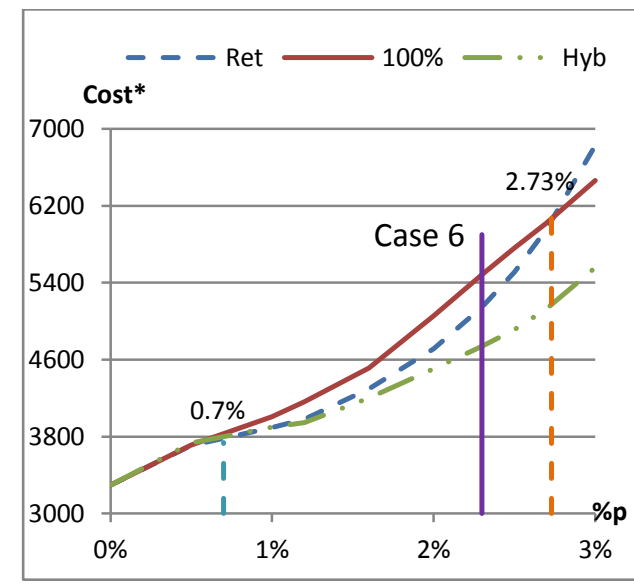

Fig. 13: Cost $^{*}=\mathrm{f}(\% \mathrm{p})$, case $\delta=\operatorname{Expo}(2), \mathrm{c}=3, \mathrm{c}_{\mathrm{insp}}=\mathbf{2 2} \$ / \mathrm{u}$

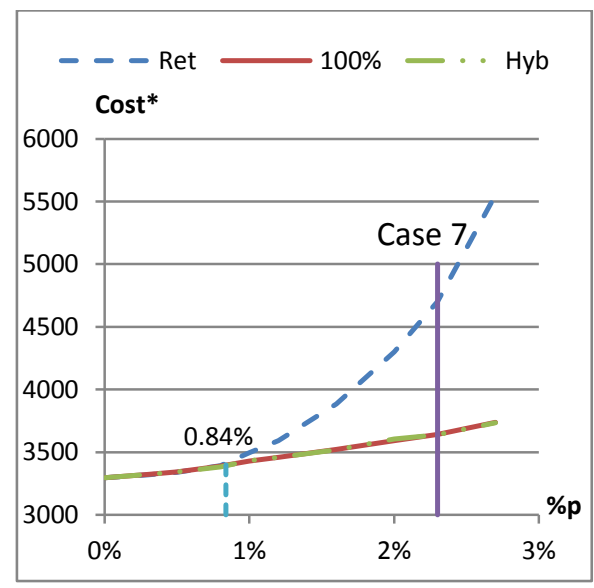

Fig. 14: $\operatorname{Cost}^{*}=\mathrm{f}(\% \mathrm{p})$, case $\delta=$ $\operatorname{Expo}(2), c=3, c_{i n s p}=0 \$ / u$

\subsection{Effect of the inspection plan severity}

Despite the variation of the acceptance number $c$, Fig. 15 and Fig. 16 present the same variation as the curves of Fig. 12. First, for $\% \mathrm{p} \leq 0.54 \%$ (Fig. 15) and $\% \mathrm{p} \leq 0.1 \%$ (Fig. 16), $\overline{\mathrm{C}}_{\mathrm{Hyb}}^{*} \simeq \overline{\mathrm{C}}_{100 \%}^{*} \simeq \overline{\mathrm{C}}_{\text {Ret }}^{*}$ Second, for \%p $>0.54 \%$ (Fig. 15) and \%p $>0.1 \%$ (Fig. 16), the Hyb policy is the most preferred one. In fact, the determination of the confidence interval for case 8 (Fig. 15) and case 9 (Fig. 16) already confirmed that $C I_{\text {Ret-Hyb }}>0$ and $C I_{100 \%-H y b}>0$. Finally, the Ret and $100 \%$ curves show a switching point at $\% \mathrm{p}=1.74 \%$ (Fig. 15) and $\% \mathrm{p}=1.03 \%$ (Fig. 16) below which $\overline{\mathrm{C}}_{\mathrm{Ret}}^{*}<\overline{\mathrm{C}}_{100 \%}^{*}$, and above which $\overline{\mathrm{C}}_{100 \%}^{*}<\overline{\mathrm{C}}_{\text {Ret }}^{*}$. In Fig. 12, we noted that the switching point is at $\% \mathrm{p}=2.42 \%$. However, when the severity of the plan increases (c decreases), the probability of refusing a delivered lot increases, thus causing a decrease 
in the value of the switching point. That is why the range of the value of $\% p$ for which the Ret policy is better than the $100 \%$ policy decreases.

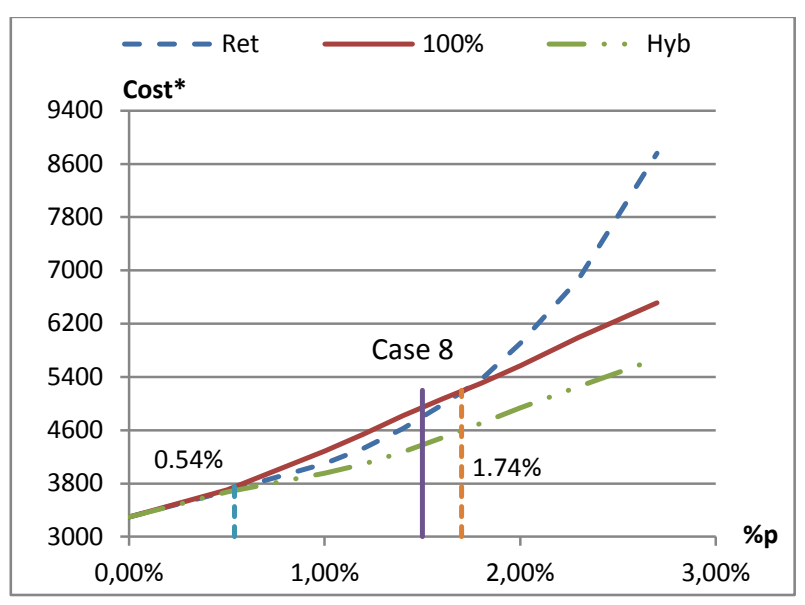

Fig. 15: $\operatorname{Cost}^{*}=\mathrm{f}(\% \mathrm{p})$, case $\delta=\operatorname{Expo}(2), \mathrm{c}=\mathbf{2}$,

$$
\mathrm{c}_{\text {insp }}=\mathbf{1 8} \$ / u
$$

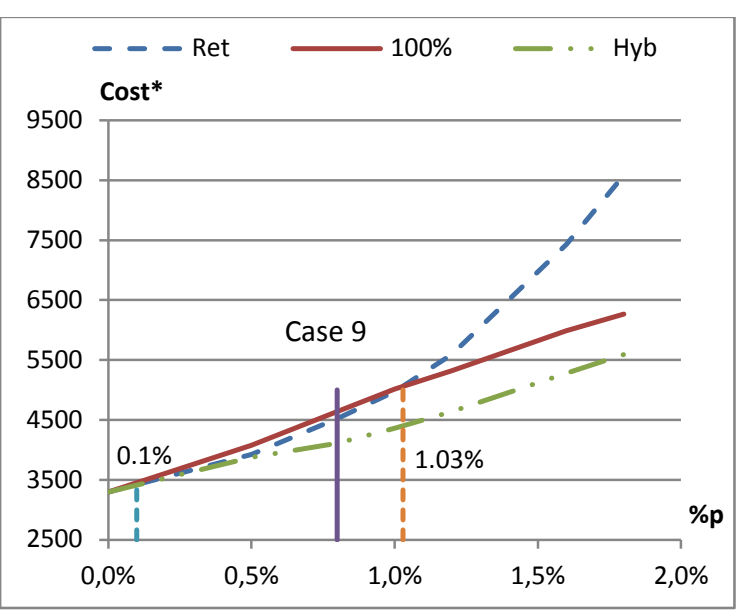

Fig. 16: Cost $^{*}=\mathrm{f}(\% \mathrm{p})$, case $\delta=\operatorname{Expo}(2)$, $\mathrm{c}=1, \mathrm{c}_{\text {insp }}=18 \$ / \mathrm{u}$

\subsection{Summary of the results}

The results of section 7 are summarised in Table 5. In the previous sections, we noticed two distinguished points corresponding to different percentages of non-conforming raw material, $\% \mathrm{p}_{\mathrm{A}}$ and $\% \mathrm{p}_{\mathrm{B}}$, where:

- If $\% \mathrm{p} \leq \% \mathrm{p}_{\mathrm{A}}$, the received lot has a good quality

- If $\% p>\% p_{B}$ : the received lot has a bad quality

- If $\% \mathrm{p}_{\mathrm{A}}<\% \mathrm{p}<\% \mathrm{p}_{\mathrm{B}}$ : the received lot has an intermediate quality

Table 5 : Summary of quality policies comparison

\begin{tabular}{|c|l|}
\hline \multicolumn{2}{|c|}{$100 \%$ or Ret policy may be avoided } \\
\hline General case & $>$ For $\% \mathrm{p} \leq \% \mathrm{p}_{\mathrm{A}}: \overline{\mathrm{C}}_{\mathrm{Hyb}}^{*} \simeq \overline{\mathrm{C}}_{100 \%}^{*} \simeq \overline{\mathrm{C}}_{\text {Ret }}^{*}$ \\
& $>$ For $\% \mathrm{p}_{\mathrm{A}}<\% \mathrm{p}<\% \mathrm{p}_{\mathrm{B}}: \overline{\mathrm{C}}_{\mathrm{Hyb}}^{*}<\overline{\mathrm{C}}_{\mathrm{Ret}}<\overline{\mathrm{C}}_{100 \%}^{*}$ \\
& $>$ For $\% \mathrm{p}>\mathrm{p}_{\mathrm{B}}: \overline{\mathrm{C}}_{\mathrm{Hyb}}^{*}<\overline{\mathrm{C}}_{100 \%}^{*}<\overline{\mathrm{C}}_{\mathrm{Ret}}^{*}$ \\
\hline & Only $100 \%$ or Ret must be avoided \\
\hline$\delta=0$ & $>$ For $\% \mathrm{p}>\% \mathrm{p}_{\mathrm{A}}:\left(\overline{\mathrm{C}}_{\mathrm{Hyb}}^{*} \simeq \overline{\mathrm{C}}_{\mathrm{Ret}}^{*}\right)<\overline{\mathrm{C}}_{100 \%}^{*}$ \\
\hline $\mathrm{c}_{\text {insp }}=0 \$ / \mathrm{u}$ & $>$ For $\% \mathrm{p}>\% \mathrm{p}_{\mathrm{A}}:\left(\overline{\mathrm{C}}_{\mathrm{Hyb}}^{*} \simeq \overline{\mathrm{C}}_{100 \%}^{*}\right)<\overline{\mathrm{C}}_{\mathrm{Ret}}^{*}$ \\
\hline
\end{tabular}


Based on these summarised results, we can confirm that the Hyb policy is always preferred. In fact it gives a lower cost than the classic policies (Ret and 100\%) or at least equal to the best of them. However, the preference between 100\% and Ret policies depends on the different supply chain parameters.

\section{Conclusions}

In this study, we have developed, in a stochastic dynamic context, an integrated production, replenishment and quality inspection control policy to minimize the total cost of a three-stage supply chain with an unreliable manufacturer and imperfect quality of raw materials. Production, replenishment and inspection decisions are all made at the manufacturer stage. When a lot of raw materials is received, a lot-by-lot acceptance sampling plan is applied, after which the decision taken regarding rejected sampled lot is: $100 \%$ screening (100\% policy), discarding (Return policy) or a Hybrid policy, where the decision maker can choose either the $100 \%$ inspection or return decision, depending on the available information regarding the finished product stock level. Due to the high stochastic level of the considered supply chain and the variability of the inspection decisions, we have used a combined approach based on simulation model and response surface methodology to optimize the control parameters of the three policies.

As a three stage supply chain is considered, the quality decision should not be taken independently of the whole system. In this paper, a comparative study between the three inspection decisions has shown that the new proposed control policy (Hyb policy) is more advantageous than the two other standard quality control policies (100\% inspection and return) in terms of total cost. In reality, such a policy allows the decision maker to decrease the total costs, depending on the entire supply chain. Regarding the 100\% and Ret policies, the decision maker should study both of them before adopting a final decision. In fact, by considering the supply chain parameters, any one policy could be more preferred than the other. However, when the percentage of non-confirming raw material items is high, performing a $100 \%$ inspection on the refused lots ensures fewer costs than the return decision. 
The present work might be extended in several directions. One may consider other detailed sample plans such as double and sequential sampling plans. An alternative extension might be to incorporate the presence of several suppliers where we can switch from one supplier to another based on cost, delay, quality and the system state.

\section{References}

Al-Salamah, M., 2011. Economic order quantity with imperfect quality, destructivetesting acceptance sampling, and inspection errors. Advances in Management \& Applied Economics 1, 59-75.

Banks, J., 2009. Discrete-event system simulation, 5th ed.. ed. Pearson Prentice Hall, Upper Saddle River, N.J.

Ben-Daya, M., Al-Nassar, A., 2008. An integrated inventory production system in a three-layer supply chain. Production Planning \& Control 19, 97-104.

Ben-Daya, M., Noman, S.M., 2008. Integrated inventory and inspection policies for stochastic demand. European Journal of Operational Research 185, 159-169.

Berthaut, F., Gharbi, A., Pellerin, R., 2009. Joint hybrid repair and remanufacturing systems and supply control. International Journal of Production Research 48, 41014121.

Bouslah, B., Gharbi, A., Pellerin, R., 2013. Joint optimal lot sizing and production control policy in an unreliable and imperfect manufacturing system. International Journal of Production Economics 144, 143-156.

Gholami-Qadikolaei, A., Mirzazadeh, A., Tavakkoli-Moghaddam, R., 2013. A stochastic multiobjective multiconstraint inventory model under inflationary condition and different inspection scenarios. Proceedings of the Institution of Mechanical Engineers, Part B: Journal of Engineering Manufacture 227, 1057-1074.

Hajji, A., Gharbi, A., Artiba, A., 2011a. Impact of random delay on Replenishment and production control strategies, Logistics (LOGISTIQUA), 2011 4th International Conference on, pp. 341-348.

Hajji, A., Gharbi, A., Kenne, J.P., Pellerin, R., 2011b. Production control and replenishment strategy with multiple suppliers. European Journal of Operational Research 208, 67-74.

Hajji, A., Gharbi, A., Kenne, J.P., 2009. Joint replenishment and manufacturing activities control in a two stage unreliable supply chain. International Journal of Production Research 47, 3231-3251.

Kenné, J.P., Boukas, E.K., Gharbi, A., 2003. Control of production and corrective maintenance rates in a multiple-machine, multiple-product manufacturing system. Mathematical and Computer Modelling 38, 351-365.

Khan, M., Jaber, M.Y., Ahmad, A.R., 2014. An integrated supply chain model with errors in quality inspection and learning in production. Omega 42, 16-24.

Konstantaras, I., Skouri, K., Jaber, M.Y., 2012. Inventory models for imperfect quality items with shortages and learning in inspection. Applied Mathematical Modelling 36, 5334-5343.

Lavoie, P., Gharbi, A., Kenné, J.P., 2010. A comparative study of pull control mechanisms for unreliable homogenous transfer lines. International Journal of 
Production Economics 124, 241-251.

Law, A.M., 2007. Simulation modeling and analysis, 4th ed.. ed. McGraw-Hill, Boston.

Lee, W., 2005. A joint economic lot size model for raw material ordering, manufacturing setup, and finished goods delivering. Omega 33, 163-174.

Montgomery, D.C., 2013. Design and analysis of experiments, 8th ed.. ed. John Wiley \& Sons, Inc., Hoboken, NJ.

Pal, A., Chan, F.T.S., Mahanty, B., Tiwari, M.K., 2010. Aggregate procurement, production, and shipment planning decision problem for a three-echelon supply chain using swarm-based heuristics. International Journal of Production Research 49, 2873 2905.

Pal, B., Sana, S.S., Chaudhuri, K., 2012. Three-layer supply chain - A productioninventory model for reworkable items. Applied Mathematics and Computation 219, 530-543.

Pegden, C.D., 1995. Introduction to Simulation using SIMAN, 2nd ed. ed. McGraw-Hill, New York.

Pellerin, R., Sadr, J., Gharbi, A., Malhamé, R., 2009. A production rate control policy for stochastic repair and remanufacturing systems. International Journal of Production Economics 121, 39-48.

Rivera-Gómez, H., Gharbi, A., Kenné, J.P., 2013. Joint production and major maintenance planning policy of a manufacturing system with deteriorating quality. International Journal of Production Economics 146, 575-587.

Rosenblatt, M.J., Lee, H.L., 1986. Economic production cycles with imperfect production processes. IIE transactions 18, 48-55.

Sajadieh, M.S., Fallahnezhad, M.S., Khosravi, M., 2013. A joint optimal policy for a multiple-suppliers multiple-manufacturers multiple-retailers system. International Journal of Production Economics 146, 738-744.

Sana, S.S., 2011. A production-inventory model of imperfect quality products in a threelayer supply chain. Decision Support Systems 50, 539-547.

Sana, S.S., Chedid, J.A., Navarro, K.S., 2014. A three layer supply chain model with multiple suppliers, manufacturers and retailers for multiple items. Applied Mathematics and Computation 229, 139-150.

Sawik, T., 2009. Coordinated supply chain scheduling. International Journal of Production Economics 120, 437-451.

Schilling, E.G., Neubauer, D.V., 2009. Acceptance sampling in quality control, 2nd ed. ed. CRC Press, Boca Raton.

Sethi, S.P., Zhang, H., 1999. Average-Cost Optimal Policies for an Unreliable Flexible Multiproduct Machine. Int J Flex Manuf Syst 11, 147-157.

Song, D.P., 2009. Optimal integrated ordering and production policy in a supply chain with stochastic lead-time, processing-time, and demand. Automatic Control, IEEE Transactions on 54, 2027-2041.

Song, D.P., 2013. Optimal Control and Optimization of Stochastic Supply Chain Systems. Springer London, London.

Starbird, S.A., 1997. Acceptance sampling, imperfect production, and the optimality of zero defects. Naval Research Logistics (NRL) 44, 515-530.

Starbird, S.A., 2005. Moral hazard, inspection policy, and food safety. American Journal of Agricultural Economics 87, 15-27. 
Wan, H., Xu, X., Ni, T., 2013. The incentive effect of acceptance sampling plans in a supply chain with endogenous product quality. Naval Research Logistics (NRL) 60, 111-124. 